\title{
The anti-aging factor Klotho protects against acquired long QT syndrome induced by uremia and promoted by fibroblast growth factor 23
}

José Alberto Navarro-García1, Rafael Salguero-Bodes ${ }^{2,3,4}$, Laura González-Lafuente1, Laura Martín-Nunes ${ }^{5}$, Elena Rodríguez-Sánchez ${ }^{1}$, Teresa Bada-Bosch ${ }^{6}$, Eduardo Hernández ${ }^{6}$, Evangelina Mérida-Herrero ${ }^{6}$, Manuel Praga ${ }^{6}$, Jorge Solís ${ }^{2,4}$, Fernando Arribas ${ }^{2,4}$, Héctor Bueno ${ }^{2,3,4,7}$, Makoto Kuro-O ${ }^{8}$, María Fernández-Velasco ${ }^{9}$, Luis Miguel Ruilope ${ }^{1,4,10}$, Carmen Delgado ${ }^{5^{*}}$ and Gema Ruiz-Hurtado ${ }^{1,4^{*}}$ (D)

\begin{abstract}
Background: Chronic kidney disease (CKD) is associated with increased propensity for arrhythmias. In this context, ventricular repolarization alterations have been shown to predispose to fatal arrhythmias and sudden cardiac death. Between mineral bone disturbances in CKD patients, increased fibroblast growth factor (FGF) 23 and decreased Klotho are emerging as important effectors of cardiovascular disease. However, the relationship between imbalanced FGF23-Klotho axis and the development of cardiac arrhythmias in CKD remains unknown.

Methods: We carried out a translational approach to study the relationship between the FGF23-Klotho signaling axis and acquired long QT syndrome in CKD-associated uremia. FGF23 levels and cardiac repolarization dynamics were analyzed in patients with dialysis-dependent CKD and in uremic mouse models of 5/6 nephrectomy (Nfx) and Klotho deficiency (hypomorphism), which show very high systemic FGF23 levels.

Results: Patients in the top quartile of FGF23 levels had a higher occurrence of very long QT intervals (> $490 \mathrm{~ms}$ ) than peers in the lowest quartile. Experimentally, FGF23 induced QT prolongation in healthy mice. Similarly, alterations in cardiac repolarization and QT prolongation were observed in Nfx mice and in Klotho hypomorphic mice. QT prolongation in Nfx mice was explained by a significant decrease in the fast transient outward potassium $\left(\mathrm{K}^{+}\right)$current $\left(I_{\text {tof }}\right)$, caused by the downregulation of $\mathrm{K}^{+}$channel 4.2 subunit (Kv4.2) expression. KV4.2 expression was also significantly reduced in ventricular cardiomyocytes exposed to FGF23. Enhancing Klotho availability prevented both long QT prolongation and reduced I tof Current. Likewise, administration of recombinant Klotho blocked the downregulation of Kv4.2 expression in Nfx mice and in FGF23-exposed cardiomyocytes.
\end{abstract}

\footnotetext{
* Correspondence: carmen.delgado@csic.es; gemaruiz@h12o.es

${ }^{5}$ Biomedical Research Institute Alberto Sols (CSIC-UAM)/CIBER-CV, Arturo Duperier 4, 28029 Madrid, Spain

${ }^{1}$ Cardiorenal Translational Laboratory, Institute of Research imas12, Hospital Universitario 12 de Octubre, Avenida de Córdoba s/n, 28041 Madrid, Spain Full list of author information is available at the end of the article
}

C The Author(s). 2022 Open Access This article is licensed under a Creative Commons Attribution 4.0 International License, which permits use, sharing, adaptation, distribution and reproduction in any medium or format, as long as you give appropriate credit to the original author(s) and the source, provide a link to the Creative Commons licence, and indicate if changes were made. The images or other third party material in this article are included in the article's Creative Commons licence, unless indicated otherwise in a credit line to the material. If material is not included in the article's Creative Commons licence and your intended use is not permitted by statutory regulation or exceeds the permitted use, you will need to obtain permission directly from the copyright holder. To view a copy of this licence, visit http://creativecommons.org/licenses/by/4.0/ The Creative Commons Public Domain Dedication waiver (http://creativecommons.org/publicdomain/zero/1.0/) applies to the data made available in this article, unless otherwise stated in a credit line to the data. 
Conclusion: The FGF23-Klotho axis emerges as a new therapeutic target to prevent acquired long QT syndrome in uremia by minimizing the predisposition to potentially fatal ventricular arrhythmias and sudden cardiac death in patients with CKD.

Keywords: CKD, Dialysis, FGF23, Klotho, Long QT, Potassium channels

\section{Background}

The risk of cardiovascular disease and mortality increases as renal function declines $[1,2]$, with the highest risk in patients with dialysis-dependent chronic kidney disease (CKD) [3]. In addition, patients with dialysisdependent CKD frequently develop mineral bone disorders (MBDs), which aggravate the decline in kidney function [4]. Among the components of bone mineral metabolism, fibroblast growth factor (FGF) 23 appears to be an important contributor to the elevated cardiovascular risk in patients with CKD [5, 6], especially for those receiving dialysis [7]. Dialysis patients have high serum levels of FGF23 [8]. Nevertheless, the causal role of FGF23 on cardiovascular risk remains unclear [9]. FGF23 is a bone-derived hormone that is stimulated in response to high serum phosphate levels and binds to FGF receptors (FGFRs) in the kidney to trigger phosphate excretion. FGF23 binding to FGFR requires the presence of the cofactor Klotho [10], a powerful regulator of aging and life-span [11]. Klotho is a transmembrane protein expressed mainly in kidney [11], although a soluble form is released into circulation by the action of secretases [12]. Soluble Klotho has several pleiotropic functions that are poorly understood, including an apparently cardioprotective action [13]. Reduced Klotho expression in CKD leads to resistance to the phosphaturic effect of FGF23 [14], increasing serum phosphate levels that pathologically stimulate FGF23 synthesis. Accordingly, CKD-related MBDs drive a premature aging phenotype in patients with CKD as consequence of the increase in pro-aging factors such as phosphates and FGF23 and the decrease in anti-aging factors including Klotho $[15,16]$. Indeed, CKD promotes the greatest discrepancy between chronological and biological age, and it has been reported that cardiovascular mortality in 20year-old dialysis patients is similar to that of healthy 80 year-olds [17]. As aging is an independent cardiovascular disease risk factor [18], CKD-related premature aging may additionally increase cardiovascular risk in patients with this pathology.

Renal dysfunction is linked to high cardiovascular risk, morbidity and mortality, at least in part, due to the high prevalence of heart failure (HF) and arrhythmias observed in patients with CKD $[3,19]$. Indeed, cardiovascular deaths account for about $50 \%$ of all deaths in CKD, which are principally due to fatal ventricular arrhythmias [20]. The QT interval represents the electrical activity corresponding to the duration of the ventricular depolarization and repolarization phases of electrocardiogram (ECG). Prolonged QT intervals increase the risk of the polymorphic ventricular tachycardia as Torsades de Pointes, sudden cardiac death (SCD), and all-cause mortality in the general population [21]. It is well established that the prevalence of prolonged QT interval increases as renal function deteriorates [22]. Dialysis patients frequently develop long QT syndrome [23, 24]. In patients on dialysis, prolonged rate-corrected QT (QTc) duration has been associated with all-cause [25] and cardiovascular mortality independently of other risk factors [23]. Many factors can influence cardiac repolarization in CKD including hypertension, diabetes mellitus, HF, electrolyte disorders, and drug abuse [26-29]. However, the influence of the mineral metabolism component FGF23 on cardiac repolarization and the putative cardioprotective role of Klotho are still unknown.

In the present study, we characterized the underlying mechanisms and factors involved directly in prolonged cardiac repolarization in clinical and experimental uremia, and we tested the hypothesis that improving the bioavailabity of the antiaging factor Klotho would prevent the electrical repolarization disturbances related to uremia.

\section{Methods}

\section{Clinical study in patients with dialysis-dependent CKD}

The study population included a total of 33 patients (17 men and 16 women) with dialysis-dependent CKD, corresponding to the complete dialysis cohort of patients receiving ambulatory dialysis in the Dialysis Service of Hospital Universitario 12 de Octubre. Inclusion criteria were age $\geq 18$ years and being on the chronic dialysis treatment while the presence of clinical diagnosis of atrial fibrillation was an exclusion criteria. Patients were 19-87 years of age. The causes of renal failure were: chronic glomerulonephritis (24.5\%), diabetic nephropathy $(18.9 \%)$, interstitial nephritis (11.3\%), nephroangiosclerosis (11.3\%), polycystic kidney disease (5.7\%), ischemic nephropathy (5.7\%), malignant hypertension (5.7\%), atypical hemolytic uraemic syndrome (3.8\%), and others (13.1\%). Blood samples were collected in EDTA tubes before starting dialysis therapy. Clinical biochemical parameters including cholesterol, calcium, phosphorus, 25-hydroxyvitamin D, and parathyroid hormone were measured by the Biochemistry Service of Hospital 
Universitario 12 de Octubre. Serum levels of C-terminal human FGF23 were measured by ELISA (Immunotopics Inc.). Patients were grouped into four quartiles according to the systemic levels of FGF23. ECGs were recorded using a 12-lead Holter Monitoring Device (CardioScan Premier 12, DM Software). ECGs were recorded for 48 $\mathrm{h}$, from $1 \mathrm{~h}$ before starting dialysis therapy to the beginning of the next dialysis session. The recordings were analyzed and interpreted using specific software tools under the supervision of two cardiologists specialized in arrhythmology from the Cardiology Department of Hospital Universitario 12 de Octubre. QTc calculations were performed for every single beat during $48 \mathrm{~h}$ Holter recordings, and the variable of QTc for every particular patient was showed as a Gaussian distribution of measurements. Automatic beat-to-beat QTc measurements from all patients were classified according to the duration of the interval as not prolonged $(\leq 450 \mathrm{~ms})$, mildly prolonged (450-490 ms), and prolonged $(>490 \mathrm{~ms})$ for analysis [30, 31]. The cut-off for long QT interval of 450 ms was used as previously described [32] and independently of the sex as it has been described that in population older than 40 years gender differences for QT interval become smaller [33]. The $\mathrm{TpTe}$ interval was measured manually following the "tangent" method in lead $V_{5}$. This method measures the TpTe interval as the distance between the maximum positive or negative deflection of the T-wave from the isoelectric line and the intersection of the tangent to the downslope of the Twave with the isoelectric line [34]. All measurements were carried out blinded to other patient data.

\section{Animal study}

Animals were maintained at controlled temperature $\left(23-25^{\circ} \mathrm{C}\right)$ on a 12 -h light/dark cycle with ad libitum access to water and a standard diet (ROD14, Altromin Spezialfutter $\mathrm{GmbH} \&$ Co. KG). Animals were housed in groups of 4 per cage of $553 \mathrm{~cm}^{2}$ by $20.8 \mathrm{~cm}$ depth (polysulfone cage type II L, SODISPAN) with standard wood chip (ECO-PURE 7 Chips, Tapvei ${ }^{\circ}$ ).

Adult 14-week-old male C57BL/6 J mice (Charles River Laboratories International Inc.) were used to study the effect of FGF23 on heart rhythm by a single-dose intraperitoneal injection of recombinant mouse FGF23 $(40 \mu \mathrm{g} / \mathrm{kg})$ (R\&D Systems) during ECG recording.

\section{Experimental CKD model by 5/6 nephrectomy}

Adult six-week-old male C57BL/6 J mice (Charles River Laboratories International Inc.) underwent sham or $5 / 6$ nephrectomy (Nfx) surgery to induce CKD. Nfx was performed in a two-step surgery under isoflurane anesthesia $(1.5 \% \mathrm{v} / \mathrm{v}$, isoflurane/oxygen) as described [35]. After each surgery, a single dose subcutaneous injection of meloxicam $(0.06 \mathrm{~mL} / \mathrm{kg})$ was used as analgesia. Sham and Nfx mice were randomly divided into two groups and treated daily with an intraperitoneal injection of vehicle solution $(0.9 \%$ sodium chloride) or recombinant mouse Klotho ( $\mathrm{rKL}, 0.01 \mathrm{mg} / \mathrm{kg} /$ day) [36] immediately after the second surgery and during 6 weeks. Mice were sacrificed six weeks after the second surgery. Similarly, 6-week-old male transgenic overexpressing Klotho mice $(T g-K l)$ mice underwent Sham or Nfx surgery as described and no additional treatment was used.

\section{Macroscopic parameters and serum biochemistry}

Heart weight (HW) to body weight (BW) ratio was calculated as an index of cardiac hypertrophy. Cardiomyocyte surface area was measured as the total cell area using images obtained from confocal microscopy (MetaZeiss LSM 510, objective w.i. 40×, n.a. 1.2). Blood samples were collected in EDTA tubes just prior to sacrifice. Blood samples were centrifuged at $2500 \mathrm{rpm}$ for $10 \mathrm{~min}$ at $4{ }^{\circ} \mathrm{C}$ for plasma collection. Plasma levels of urea and blood urea nitrogen (BUN) (BioAssays System), phosphorus (Abcam), and FGF23 (Immunotopics Inc.) were measured by ELISA.

\section{Electrocardiogram}

ECGs registries were made using a Small Animal Physiological Monitoring System (Harvard Apparatus). ECGs were recorded from mice lightly anesthetized with isoflurane $(1.5 \% \mathrm{v} / \mathrm{v}$, isoflurane/oxygen) the day before the sacrifice. Mice were located in prone position on the pre-heated pad at $37^{\circ} \mathrm{C}$ for the registry, placed on the metal pads of ECG sensors. Paws were covered with conductive gel to guarantee an optimal electrical connection. A cross-platform Java program was used to convert ECG registries into LabChart binary. Converted files were analyzed using LabChart 7.0 software (ADInstruments). QT, JT, and TpTe interval measurements were obtained from LabChart analysis. QT interval duration was corrected using the Mitchell formula [37]:

$$
Q T c=\frac{Q T}{\sqrt{\frac{R R}{100}}}
$$

where QTc is the corrected QT interval, QT is the interval between $\mathrm{Q}$ wave and $\mathrm{T}$ wave end, and $\mathrm{RR}$ is the interval between one $\mathrm{R}$ wave and the $\mathrm{R}$ wave of the next QRS complex.

\section{Adult mouse ventricular myocyte isolation}

Mice were heparinized and anaesthetized with ketamine $(100 \mathrm{mg} / \mathrm{kg})$ and xylazine $(10 \mathrm{mg} / \mathrm{kg})$ via intraperitoneal injection. Hearts from anesthetized mice were rapidly removed and cannulated via the ascending aorta onto a Langendorff perfusion system. Hearts were retrograde 
perfused for $3 \mathrm{~min}$ with calcium-free Tyrode's solution supplemented with EGTA $(0.2 \mathrm{mmol} / \mathrm{L})$ and followed by Tyrode's solution containing type II collagenase $(1 \mathrm{mg} /$ $\mathrm{mL}$, Worthington), $\mathrm{CaCl}_{2}(0.1 \mathrm{mmol} / \mathrm{L})$, and BSA (1 mg/ $\mathrm{mL}$ ) for 3 to $5 \mathrm{~min}$. Hearts were removed from the apparatus and the ventricles were cut into small pieces to facilitate digestion. Digested hearts were filtered through a nylon mesh strainer $(250 \mu \mathrm{m})$ to remove pieces of tissue and finally centrifuged at room temperature at 300 $\mathrm{rpm}$ for $3 \mathrm{~min}$. The supernatant was removed and the pellet was resuspended in Tyrode's solution with $\mathrm{CaCl}_{2}$ $(0.5 \mathrm{mmol} / \mathrm{L})$ and BSA $(2 \mathrm{mg} / \mathrm{mL})$ and centrifuged again. The resulting pellet was resuspended in Tyrode's solution with $\mathrm{CaCl}_{2}(1 \mathrm{mmol} / \mathrm{L})$ and BSA $(2 \mathrm{mg} / \mathrm{mL})$. Tyrode's solution composition was (in $\mathrm{nM}$ ) as follows: 130 $\mathrm{NaCl}, 5.4 \mathrm{KCl}, 0.4 \mathrm{NaH}_{2} \mathrm{PO}_{4}, 0.5 \mathrm{MgCl}_{2}, 35$ HEPES, and 22 glucose, and $\mathrm{pH}$ was adjusted to 7.4 using $\mathrm{LiOH}$ [38].

\section{Neonatal mouse ventricular myocyte isolation}

Cells were isolated from a total of 12 mice using the Pierce Primary Cardiomyocyte Isolation Kit (ThermoScientific). Isolated neonatal cardiomyocytes were maintained in culture for 5 days. On day 5 , neonatal cardiomyocytes where preincubated for $3 \mathrm{~h}$ with vehicle or $\mathrm{rKL}(100 \mathrm{ng} / \mathrm{mL})$ and then incubated with vehicle or FGF23 $(100 \mathrm{ng} / \mathrm{mL})$ for $48 \mathrm{~h}$. Neonatal cardiomyocytes were then harvested and centrifuged at $1000 \mathrm{rpm}$ for 3 min. Supernatants were discarded and pellets were stored at $-80^{\circ} \mathrm{C}$ until use.

\section{Electrophysiological studies}

Isolated ventricular cardiomyocytes maintained in Tyrode's solution with $1 \mathrm{mmol} / \mathrm{L} \mathrm{CaCl}_{2}$ were used in electrophysiological studies within $4 \mathrm{~h}$ of isolation. The whole-cell voltage-clamp method was used. The fast transient outward current $\left(I_{t o f}\right)$ was recorded using an Axopatch 200B amplifier (Molecular Devices). The patch pipette resistance was 1.0-2 $\mathrm{M} \Omega$. Patch clamp experiments were carried out at room temperature. Current traces were digitized with Digidata 1440A and analyzed using pClamp10 software (Molecular Devices).

Current density was obtained from the normalization of the current amplitude to the membrane capacitance $(\mathrm{Cm}) . \mathrm{Cm}$ was obtained by applying $\pm 10 \mathrm{mV}$ voltage steps from $-60 \mathrm{mV}$. The following equation was used to calculate $\mathrm{Cm}$ :

$$
C m=\frac{\tau_{\mathrm{c}} \times I_{0}}{\Delta V_{m} \times\left[1-\frac{I_{\infty}}{I_{0}}\right]}
$$

where $\tau_{c}$ is the time constant of the membrane capacitance, $I_{0}$ is the maximum capacitance current value,
$\Delta V_{\mathrm{m}}$ is the amplitude of the voltage step, and $I_{\infty}$ is the amplitude of the steady-state current.

$I_{\text {tof }}$ was obtained as described [39]. Total $I_{t o}$ was obtained by the application of $300 \mathrm{~ms}$ depolarizing voltage pulses from the holding potential of $-80 \mathrm{mV}$, from $50 \mathrm{mV}$ to $+50 \mathrm{mV}$ at a frequency of $0.2 \mathrm{~Hz}$. I $I_{t o f}$ was inactivated by applying a short prepulse of $100 \mathrm{~ms}$ step at $30 \mathrm{mV}$ from a holding potential of $-80 \mathrm{mV}$, followed by depolarizing pulses from $-50 \mathrm{mV}$ to $+50 \mathrm{mV}$. I tof was calculated as the difference between the current recording with and without inactivating prepulse. The extracellular solution contained (in $\mathrm{mM}$ ) the following: 135 $\mathrm{NaCl}, 10$ glucose, 10 HEPES, $1 \mathrm{MgCl}_{2}, 1 \mathrm{CaCl}_{2}, 5.4 \mathrm{KCl}$, and $2 \mathrm{CoCl}_{2}$; the $\mathrm{pH}$ was adjusted to 7.4 with $\mathrm{NaOH}$. The pipette solution contained (in $\mathrm{mM}$ ) the following: $135 \mathrm{KCl}, 4 \mathrm{MgCl}_{2}$, 5 EGTA, 10 HEPES, 10 glucose, 5 $\mathrm{Na}_{2} \mathrm{ATP}$, and 5 disodium creatine phosphate 20 ; the $\mathrm{pH}$ was adjusted to 7.2 with $\mathrm{KOH}$.

\section{RNA isolation and quantitative real-time $P C R$}

Total RNA from adult and neonatal cardiomyocytes was isolated using TiaZol (Qiagen). Quality and quantity of isolated RNA were assessed with on the NanoDrop One Microvolume UV-Vis Spectrophotometer (ThermoFisher Scientific). Reverse-transcription using HighCapacity cDNA Reverse Transcription Kit (Applied Biosystems) was used to obtain cDNA from $2 \mu \mathrm{g}$ of RNA. cDNA samples were used for quantitative real-time PCR (qRT-PCR) using the FastStart Essential DNA Green Master (Roche) in $10 \mu \mathrm{L}$ of total reaction volume on a LightCycler 480 II (Roche) at optimized thermocycling settings. Ribosomal housekeeping gene 36b4 (RPLPO) was used to normalize relative gene expression, which was evaluated using the $2^{-\Delta \Delta C t}$ method.

Primer sequences $\left(5^{\prime}-3^{\prime}\right)$ used were as follows: mKcnd2-F: GCCGCAGCACCTAGTCGTT; m-Kcnd2-R: CACCACGTCGATGATACTCATGA; m-Rplp0-F: AGATGCAGCAGATCCGCAT; m-Rplp0-R: GTTCTT GCCCATCAGCACC.

\section{Statistics}

Experimental data are reported as mean \pm standard error of mean (SEM) and human data are presented as mean \pm standard deviation (SD). Statistical significance was estimated using unpaired Student's test, $\chi^{2}$ test, or ANOVA with Newman-Keuls multiple comparison test when appropriate. Gaussian distribution of the values was determined using Kolmogorov-Smirnov and Shapiro-Wilk tests. All $P$-values are two-tailed and $P$ values $<0.05$ were considered statistically significant. All analyses were performed using GraphPad Prism v6.0 (GraphPad Software Inc.), Origin Pro v9.0 (OriginLab Corp.), or SPSS22 (IBM). 


\section{Results}

Higher circulating FGF23 levels are associated with longer QT interval in patients with dialysis-dependent CKD

We analyzed the possible relation between serum FGF23 levels and QT interval duration in a cohort of patients with dialysis-dependent CKD. Baseline characteristics of the cohort are shown in Table 1. The mean age of patients was 61 years (51.5\% men). Serum FGF23 levels were measured in the cohort (Fig. 1A). The mean level of serum FGF23 in the cohort was $5434 \mathrm{RU} / \mathrm{mL}$, which is 100 -fold higher than that described in healthy populations [8]. We split patients into four quartiles according to serum FGF23 levels (Q1-Q4). Age, sex distribution, body mass index (BMI), and systolic and diastolic blood pressure (SBP and DBP, respectively) were similar across the four FGF23 quartiles. Also, no differences were observed in clinical history, including left ventricular hypertrophy $(\mathrm{LVH})$ or previous kidney transplantation (KT). Likewise, serum levels of cholesterol, calcium, phosphorus, 25-hydroxyvitamin D (vitamin D), parathyroid hormone, and potassium $\left(\mathrm{K}^{+}\right)$were similar across FGF23 quartiles, and no differences were evident in dialysis-related parameters or medications received. All patients underwent 12-lead Holter monitoring from $1 \mathrm{~h}$ before the beginning of a dialysis therapy to the start of the next treatment $(48 \mathrm{~h})$. When we compared patients according to FGF23 quartile, we found no differences in heart rate $(\mathrm{HR})$ or in $\mathrm{HR}$ variability metrics (SDANN, SDNN and MRSSD index) (Table 1). Likewise, no changes were observed for ECG intervals with the exception of QTc interval and T-peak to T-end (TpTe) interval duration, which is an ECG repolarization marker that has been related to increased risk of mortality [40, 41]. QTc intervals $>450 \mathrm{~ms}$ were considered prolonged QTc intervals and were called long QTc. We found that the number of patients with long QTc increased as FGF23 levels rose, with a prevalence of $25 \%$ of patients in Q1 to $75 \%$ in Q4 (Fig. 1B). Two representative ECG traces from Q1 and Q4 patients are shown in Fig. 1C. We performed an in-depth analysis of long QTc by subdividing QTc intervals into moderately long (450-490 $\mathrm{ms}$ ) and very long QTc (>490 ms). We found that the probability for very long QTc was higher as FGF23 levels increased (7\% in Q1 patients vs. 23\% in Q4, $P<0.001$, Fig. 1D). Furthermore, TpTe significantly increased with higher FGF23 levels $(P<0.05$, Table 1$)$.

\section{FGF23 prolongs ventricular repolarization and induces long QTc, JT, and TpTe intervals}

Our data thus far support the concept that FGF23 might be implicated in the prevalence of long QTc in dialysis patients. To test whether FGF23 directly induces in vivo changes in ECG repolarization dynamics, we injected a single intraperitoneal dose of vehicle solution $(0.9 \%$ sodium chloride) or $40 \mu \mathrm{g} / \mathrm{kg}$ FGF23 in healthy 14-weekold mice and recorded ECGs. We also measured serum FGF23 levels before and after ECG recording. Serum FGF23 levels increased 3.4-fold in mice injected with FGF23, from $231.2 \pm 17.0 \mathrm{pg} / \mathrm{mL}$ at baseline to $791.5 \pm$ $75.6 \mathrm{pg} / \mathrm{mL}$ at the end of ECG recording. Representative ECG traces before (black profile) and after (red profile) FGF23 injection are shown in Fig. 2A. No changes in HR were observed after FGF23 administration (data not shown). No differences were observed in QRS interval (Fig. 2B) after administration, independently of the treatment received. By contrast, QT and QTc intervals were significantly longer in mice treated with FGF23 compared with those receiving vehicle only (Fig. 2C, D). Detailed analysis of the TpTe interval and the JT interval, obtained by subtracting the QRS duration from the QT interval, showed that both were longer in mice receiving FGF23 (Fig. 2E, F).

\section{Experimental CKD triggers prolonged ventricular repolarization and reduces the repolarizing $I_{\text {tof }}$}

We used 5/6 nephrectomy (Nfx) in mice as an experimental model of chronic renal failure with comparable uremic manifestations to those seen in patients with dialysis-dependent CKD [42]. Macroscopic and biochemical parameters of Sham-operated and Nfx groups are shown in Table 2. No differences were observed in body weight (BW) between groups, and no signs of cardiac hypertrophy were evident in Nfx mice, as indicated by similar heart weight (HW), $\mathrm{HW}$ to $\mathrm{BW}$ ratio (HW/ $\mathrm{BW}$ ), and cardiomyocyte area in Sham and Nfx mice. While kidney weight (KW) was also comparable between groups, it is important to note that KW in Nfx animals corresponds to the remaining portion of the left kidney (one third) and, accordingly, the left kidney of Nfx mice was hypertrophied (Table 2). Biochemical analysis showed that urea and blood urea nitrogen (BUN) levels were significantly higher in Nfx mice compared with Sham mice $(P<0.001$, Table 2$)$, whereas no differences in phosphorus levels were apparent, likely as a consequence of the significantly higher levels of FGF23 observed in Nfx mice $(P<0.01$, Table 2$)$.

We next analyzed ventricular repolarization dynamics in vivo by ECG. Representative traces from Sham (black profile) and Nfx (red profile) mice are shown in Fig. 3A. No changes were observed in $\operatorname{HR}(463.6 \pm 9.9 \mathrm{~ms}$ vs. $457.7 \pm 13.3 \mathrm{~ms}$ for Sham and Nfx, respectively) or in QRS interval (Fig. 3B) between groups. However, Nfx mice displayed significantly prolonged ventricular repolarization characterized by prolonged QT $(P<0.01)$, QTc $(P<0.001)$, JT $(P<0.01)$, and TpTe (both $P<0.01)$ intervals as compared with Sham mice (Fig. 3C-F). Alterations in ventricular repolarization intervals are typically due to changes in the ionic currents involved in 
Table 1 Demographic data of patients with dialysis-dependent CKD by quartile of circulating FGF23 levels

\section{Fibroblast growth factor $23, \mathrm{RU} / \mathrm{mL}$}

\begin{tabular}{|c|c|c|c|c|c|}
\hline & $\begin{array}{l}\text { Q1 } \\
\text { [203.2-779.7] }\end{array}$ & $\begin{array}{l}\text { Q2 } \\
\text { [1090-3585] }\end{array}$ & $\begin{array}{l}\text { Q3 } \\
\text { [3785-6785] }\end{array}$ & $\begin{array}{l}\text { Q4 } \\
\text { [6835-27360] }\end{array}$ & $P$-value \\
\hline \multicolumn{6}{|c|}{ Demographic and clinical characteristics } \\
\hline Age (years) & $64.6 \pm 10.6$ & $68.6 \pm 14.1$ & $51.3 \pm 22.4$ & $59.0 \pm 11.8$ & 0.149 \\
\hline Male sex $(n, \%)$ & $6(75.0)$ & $3(33.3)$ & $5(62.5)$ & $3(37.5)$ & 0.264 \\
\hline BMI $\left(\mathrm{kg} / \mathrm{m}^{2}\right)$ & $24.3 \pm 4.8$ & $21.2 \pm 4.4$ & $21.3 \pm 2.6$ & $22.2 \pm 3.1$ & 0.344 \\
\hline $\mathrm{SBP}(\mathrm{mmHg})$ & $136.4 \pm 26.4$ & $139.0 \pm 13.8$ & $122.8 \pm 20.7$ & $114.8 \pm 23.1$ & 0.088 \\
\hline $\mathrm{DBP}(\mathrm{mmHg})$ & $78.1 \pm 12.0$ & $71.4 \pm 18.9$ & $76.5 \pm 22.1$ & $67.4 \pm 11.4$ & 0.568 \\
\hline \multicolumn{6}{|l|}{ Medical history $(n, \%)$} \\
\hline DM & $2(25.0)$ & $1(11.1)$ & $3(37.5)$ & $1(12.5)$ & 0.522 \\
\hline Hypertension & $7(87.5)$ & $8(88.8)$ & $5(62.5)$ & $6(75.0)$ & 0.522 \\
\hline Current smokers & $2(25.0)$ & $0(0.0)$ & $1(12.5)$ & $1(12.5)$ & 0.707 \\
\hline $\mathrm{Ml}$ & $1(12.5)$ & $1(11.1)$ & $0(0.0)$ & $2(25.0)$ & 0.235 \\
\hline Ischemia & $2(25.0)$ & $0(0.0)$ & $0(0.0)$ & $1(12.5)$ & 0.235 \\
\hline $\mathrm{LVH}$ & $4(50.0)$ & $2(22.2)$ & $5(62.5)$ & $4(50.0)$ & 0.387 \\
\hline Previous KT & $3(37.5)$ & $2(22.2)$ & $3(37.5)$ & $5(62.5)$ & 0.403 \\
\hline \multicolumn{6}{|l|}{ Laboratory measurements } \\
\hline Cholesterol (ng/mL) & $148.3 \pm 38.6$ & $141.7 \pm 26.7$ & $147.1 \pm 29.0$ & $151.6 \pm 25.0$ & 0.922 \\
\hline Calcium (ng/mL) & $9.0 \pm 0.3$ & $8.8 \pm 0.4$ & $9.1 \pm 0.5$ & $9.0 \pm 0.6$ & 0.747 \\
\hline Phosphorus (ng/mL) & $3.9 \pm 0.9$ & $4.3 \pm 1.2$ & $4.3 \pm 1.4$ & $4.9 \pm 1.2$ & 0.471 \\
\hline CaxP & $35.1 \pm 7.8$ & $38.0 \pm 10.4$ & $39.3 \pm 12.6$ & $43.2 \pm 9.5$ & 0.467 \\
\hline 25-Hydroxyvitamin D (ng/mL) & $9.9 \pm 3.1$ & $9.3 \pm 3.0$ & $11.2 \pm 4.4$ & $8.3 \pm 3.0$ & 0.412 \\
\hline Parathyroid hormone $(\mathrm{pg} / \mathrm{mL})$ & $350.4 \pm 138.4$ & $301.4 \pm 199.0$ & $475.5 \pm 251.2$ & $406.8 \pm 242.3$ & 0.444 \\
\hline $\mathrm{sKL}(\mathrm{ng} / \mathrm{mL})$ & $0.4 \pm 0.2$ & $0.3 \pm 0.1$ & $0.5 \pm 0.3$ & $0.3 \pm 0.1$ & 0.189 \\
\hline \multicolumn{6}{|l|}{ Dialysis-related parameters } \\
\hline Dialysis vintage (months) & $95.4 \pm 81.5$ & $58.2 \pm 59.3$ & $59.8 \pm 50.4$ & $100 \pm 100$ & 0.536 \\
\hline Serum creatinine (mg/dL) & $6.4 \pm 1.3$ & $7.3 \pm 2.2$ & $9.1 \pm 2.7$ & $7.7 \pm 1.9$ & 0.096 \\
\hline Serum albumin (g/dL) & $4.3 \pm 0.3$ & $3.9 \pm 0.3$ & $4.2 \pm 0.6$ & $3.9 \pm 0.4$ & 0.211 \\
\hline $\mathrm{Kt} / \mathrm{N}$ & $1.7 \pm 0.2$ & $1.6 \pm 0.3$ & $1.6 \pm 0.3$ & $1.6 \pm 0.3$ & 0.757 \\
\hline eGFR $\left(\mathrm{ml} / \mathrm{min} / 1.73 \mathrm{~m}^{2}\right)$ & $8.4 \pm 2.4$ & $6.5 \pm 3.0$ & $6.5 \pm 4.2$ & $6.3 \pm 2.0$ & 0.447 \\
\hline \multicolumn{6}{|l|}{ Medication } \\
\hline \multicolumn{6}{|l|}{ Anti-hypertensive drugs } \\
\hline ACEi/ARB (\%) & $1(12.5)$ & $3(33.3)$ & $4(50.0)$ & $1(12.5)$ & 0.260 \\
\hline Beta-blocker (\%) & $1(12.5)$ & $5(55.5)$ & $4(50.0)$ & $4(50.0)$ & 0.268 \\
\hline Diuretics (\%) & $2(25.0)$ & $0(0.0)$ & $0(0.0)$ & $1(12.5)$ & 0.235 \\
\hline \multicolumn{6}{|l|}{ Anti-arrhythmics drugs } \\
\hline Amiodarone (\%) & $0(0.0)$ & $0(0.0)$ & $1(12.5)$ & $0(0.0)$ & 0.359 \\
\hline \multicolumn{6}{|l|}{ Bone-mineral metabolism drugs } \\
\hline Calcium chelators (\%) & $1(12.5)$ & $6(66.6)$ & $5(62.5)$ & $5(62.5)$ & 0.091 \\
\hline Sevelamer (\%) & $3(37.5)$ & $4(44.4)$ & $3(37.5)$ & $3(37.5)$ & 0.989 \\
\hline Lantanum carbonate (\%) & $1(12.5)$ & $1(11.1)$ & $5(62.5)$ & $4(50.0)$ & 0.054 \\
\hline Cinacalcet (\%) & $1(12.5)$ & $3(33.3)$ & $5(62.5)$ & $4(50.0)$ & 0.349 \\
\hline Paricalcitol (\%) & $7(87.5)$ & $5(55.5)$ & $5(62.5)$ & $4(50.0)$ & 0.381 \\
\hline Colecalciferol (\%) & $1(12.5)$ & $1(11.1)$ & $0(0.0)$ & $1(12.5)$ & 0.785 \\
\hline
\end{tabular}


Table 1 Demographic data of patients with dialysis-dependent CKD by quartile of circulating FGF23 levels (Continued)

\begin{tabular}{|c|c|c|c|c|c|}
\hline \multicolumn{6}{|c|}{ Fibroblast growth factor $23, \mathrm{RU} / \mathrm{mL}$} \\
\hline & $\begin{array}{l}\text { Q1 } \\
\text { [203.2-779.7] }\end{array}$ & $\begin{array}{l}\text { Q2 } \\
\text { [1090-3585] }\end{array}$ & $\begin{array}{l}\text { Q3 } \\
\text { [3785-6785] }\end{array}$ & $\begin{array}{l}\text { Q4 } \\
{[6835-27360]}\end{array}$ & $P$-value \\
\hline Parathyroidectomy (\%) & $0(0.0)$ & $2(22.2)$ & $1(12.5)$ & $1(12.5)$ & 0.620 \\
\hline \multicolumn{6}{|c|}{ Electrocardiogram parameters } \\
\hline HR (bpm) & $78.8 \pm 9.3$ & $81.8 \pm 13.3$ & $85.8 \pm 15.8$ & $83.4 \pm 8.3$ & 0.702 \\
\hline SDANN & $83.4 \pm 30.2$ & $57.6 \pm 15.1$ & $76.0 \pm 28.0$ & $78.9 \pm 15.5$ & 0.153 \\
\hline SDNN & $37.3 \pm 16.0$ & $33.8 \pm 13.5$ & $43.0 \pm 13.5$ & $37.5 \pm 17.5$ & 0.682 \\
\hline RMSSD & $37.8 \pm 24.6$ & $45.6 \pm 23.1$ & $48.8 \pm 13.4$ & $41.5 \pm 20.8$ & 0.769 \\
\hline TpTe interval (ms) & $85.5 \pm 17.3$ & $108.9 \pm 39.7$ & $97.1 \pm 19.8$ & $136.0 \pm 45.6$ & 0.029 \\
\hline
\end{tabular}

Data from 33 patients are reported as mean \pm SD or number (percentage). BMI, body mass index; SBP, systolic blood pressure; DBP, diastolic blood pressure, DM, diabetes mellitus; MI, myocardial infarction; eGFR, estimated glomerular filtration rate; LVH, left ventricular hypertrophy; KT, kidney transplantation; eGFR, estimated glomerular filtration rate; $\mathrm{HR}$, heart rate; SDANN, Standard Deviation of the 5 minute Average NN intervals; SDNN, standard deviation of the IBI of normal sinus beats; RMSSD, root mean square of the successive differences; TpTe, T wave peak to T wave end; CaxP, calcium-phosphorus product; sKL: soluble Klotho; ACEi, angiotensin-converting enzyme inhibitor; ARB, angiotensin receptor blocker

ventricular cardiomyocyte repolarization. The most important repolarizing current in the mouse heart is the fast transient outward $\mathrm{K}^{+}$current $\left(I_{\text {tof }}\right)$. Representative recording profiles of $I_{\text {tof }}$ from adult mouse ventricular cardiomyocytes isolated from Sham (black profile, left panel) and Nfx (red profile, right panel) mice are shown in Fig. 3G. Results showed that $I_{\text {tof }}$ density was significantly lower in $\mathrm{Nfx}$ cardiomyocytes than in Sham cardiomyocytes from -10 to $+50 \mathrm{mV}(P<0.05$, Fig. $3 \mathrm{H})$.

\section{Recombinant Klotho treatment on CKD mice prevents both, the prolonged ventricular repolarization, and the reduced $I_{\text {tof }}$}

Because CKD is characterized by Klotho deficiency [43] and Nfx mice have lower Klotho levels than Sham mice $(1.2 \mathrm{ng} / \mathrm{mL} \pm 0.2$ vs. $11.9 \mathrm{ng} / \mathrm{mL} \pm 5.5$, respectively, $P<$ 0.001 ), we chose to treat $\mathrm{Nfx}$ mice chronically during 6 weeks with recombinant murine Klotho (rKL). Macroscopic and biochemical parameters are shown in Table 2. No differences were observed for BW, HW, HW/BW ratio, or cardiomyocyte area between Klotho-treated Sham (Sham+ $\mathrm{rKL})$ and Klotho-treated Nfx (Nfx + rKL) mice. Furthermore, no differences were observed between vehicle- and rKL-treated mice independently of the surgery. Analogous to the data for vehicle-mice, comparable values for KW were found for both groups, signifying that the left kidney remained hypertrophied. Furthermore, serum urea, BUN, and FGF23 levels were all significantly higher in Nfx+rKL mice than in Sham + rKL mice $(P<0.001$, Table 2$)$ with no changes to phosphorus levels. Similar values were observed in rKL-treated mice compared to vehicle ones. These data support the notion that chronic Klotho treatment fails to prevent kidney damage.

We next studied ventricular repolarization dynamics in vivo in Klotho-treated Sham and CKD mice. Representative ECG traces of Sham+rKL (grey profile) and Nfx+ rKL (pink profile) mice are shown in Fig. 4A. No changes were observed in QRS interval duration between both groups (Fig. 4B). Recombinant Klotho treatment prevented the changes in ventricular repolarization-related parameters observed in Nfx mice (QT, QTc, JT, and TpTe intervals) (Fig. $4 \mathrm{C}-\mathrm{F}$ ). We then measured $I_{\text {tof }}$ as before in isolated adult ventricular cardiomyocytes from Klothotreated mice; representative recording profiles from Sham+rKL (grey line, left panel) and Nfx+rKL (pink profile, right panel) mice are presented in Fig. 4G, showing that $I_{\text {tof }}$ density was similar in both groups (Fig. $4 \mathrm{H}$ ).

\section{Recombinant Klotho treatment counteracts the reduction in Kv4.2 expression in isolated ventricular cardiomyocytes from CKD mice and in cardiomyocytes exposed to FGF23}

As the reduced density of $I_{\text {tof }}$ in Nfx mice could be due to changes in the levels of the $\mathrm{K}^{+}$channels, we analyzed the mRNA expression of the main $\alpha$-subunit that encodes the $I_{\text {tof }}$ channel in mice, Kv4.2. Kv4.2 expression was significantly lower in ventricular myocytes from $\mathrm{Nfx}$ mice than from Sham mice $(P<0.05$, Fig. 5A). By contrast, analysis of $K v 4.2$ expression in isolated adult ventricular myocytes from Sham+rKL and Nfx+rKL mice revealed no significant difference in levels between both groups (Fig. 5A). However, Kv4.2 expression was found significantly higher in Nfx+rKL compared to Nfx group $(P<0.05$, Fig. $5 \mathrm{~A})$.

The mineral bone component FGF23 is a uremic factor known to be directly involved in cardiac (including cardiomyocyte) damage [44, 45]. We therefore studied the direct effect of FGF23 on $\mathrm{K}^{+}$channel expression in healthy cardiomyocytes. Because the prolonged culture of adult ventricular cardiomyocytes results in poor survival and loss of phenotype [46], we used neonatal mouse ventricular myocytes to analyze the effect of FGF23 on Kv4.2 expression. The results showed that Kv4.2 expression was significantly lower in neonatal mouse cardiomyocytes exposed to $100 \mathrm{ng} / \mathrm{mL}$ FGF23 for $48 \mathrm{~h}$ than to vehicle solution $(P<0.05$, Fig. $5 \mathrm{~B})$, 


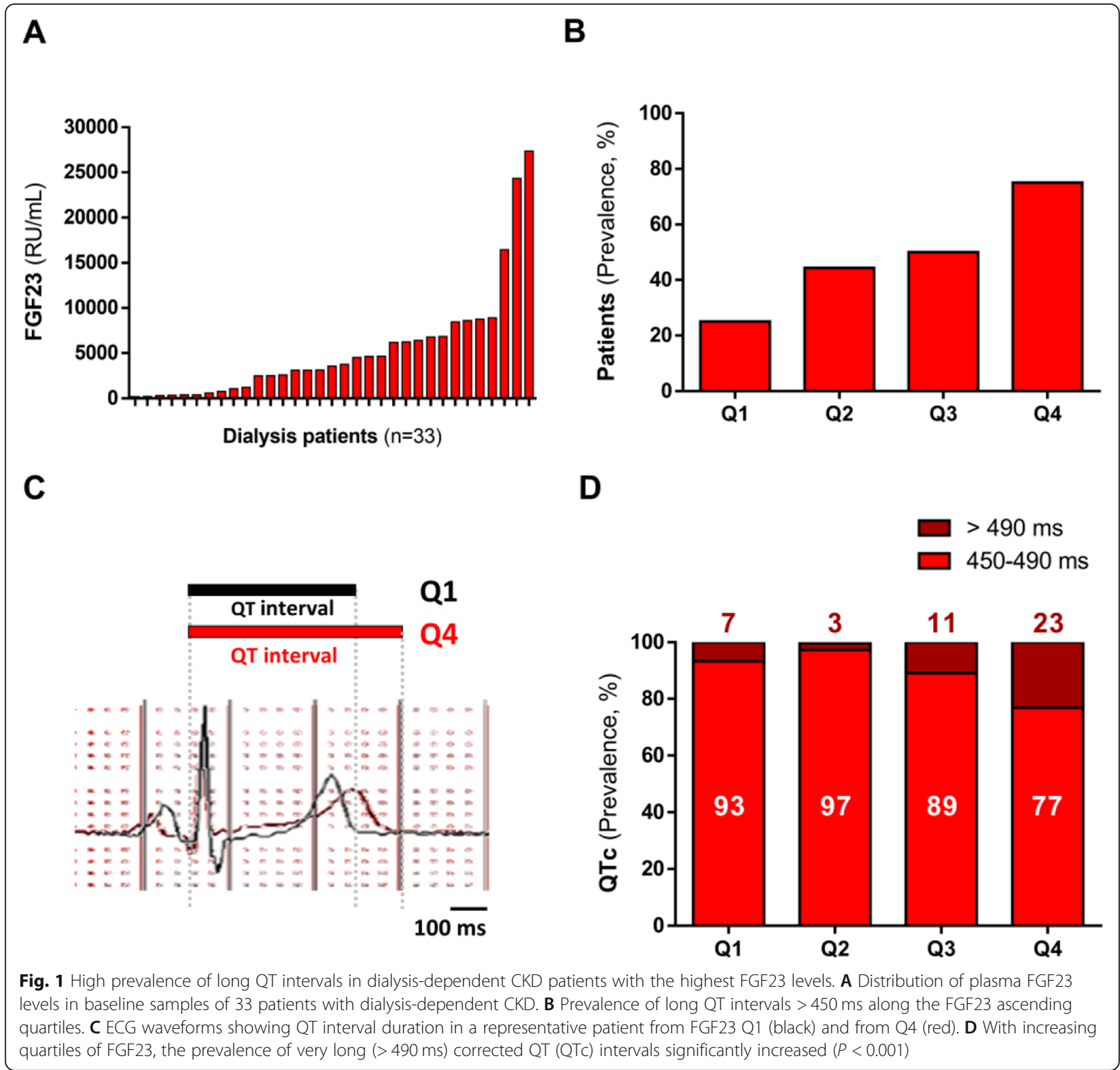

suggesting that FGF23 represses $K v 4.2$ channel subunit expression. By contrast, neonatal cardiomyocytes preincubated with recombinant Klotho prior to exposure with FGF23 did not show a decrease in $K v 4.2$ subunit expression (Fig. 5B), and expression was significantly higher than in cells incubated only with FGF23 $(P<$ 0.05, Fig. 5B).

Klotho overexpression prevents prolonged ventricular repolarization in CKD mice, and transgenic mice with reduced Klotho expression exhibit prolonged ventricular repolarization

Given the above findings, we next sought to analyze the ventricular repolarization-related parameters in a transgenic mouse model characterized by enhanced endogenous Klotho expression. Klotho-overexpressing mice $(T g-K l)$ underwent $\mathrm{Nfx}$ surgery to investigate whether high endogenous Klotho levels would prevent the prolongation of the QT interval induced by CKD. Macroscopic and biochemical parameters of Sham- Tg-Kl and $\mathrm{Nfx}-\mathrm{Tg}-\mathrm{Kl}$ groups are shown in Additional File 1. No differences were observed in BW, HW, and HW/BW ratio between the two groups and, as before, similar values of KW were found between both groups indicating that the left kidney remained hypertrophied. Biochemical analysis revealed significantly higher levels of urea, BUN, and FGF23 in Nfx- $T g-K l$ mice than in Sham$T g-K l$ mice $(P<0.01$, Additional File 1$)$ with no evident 


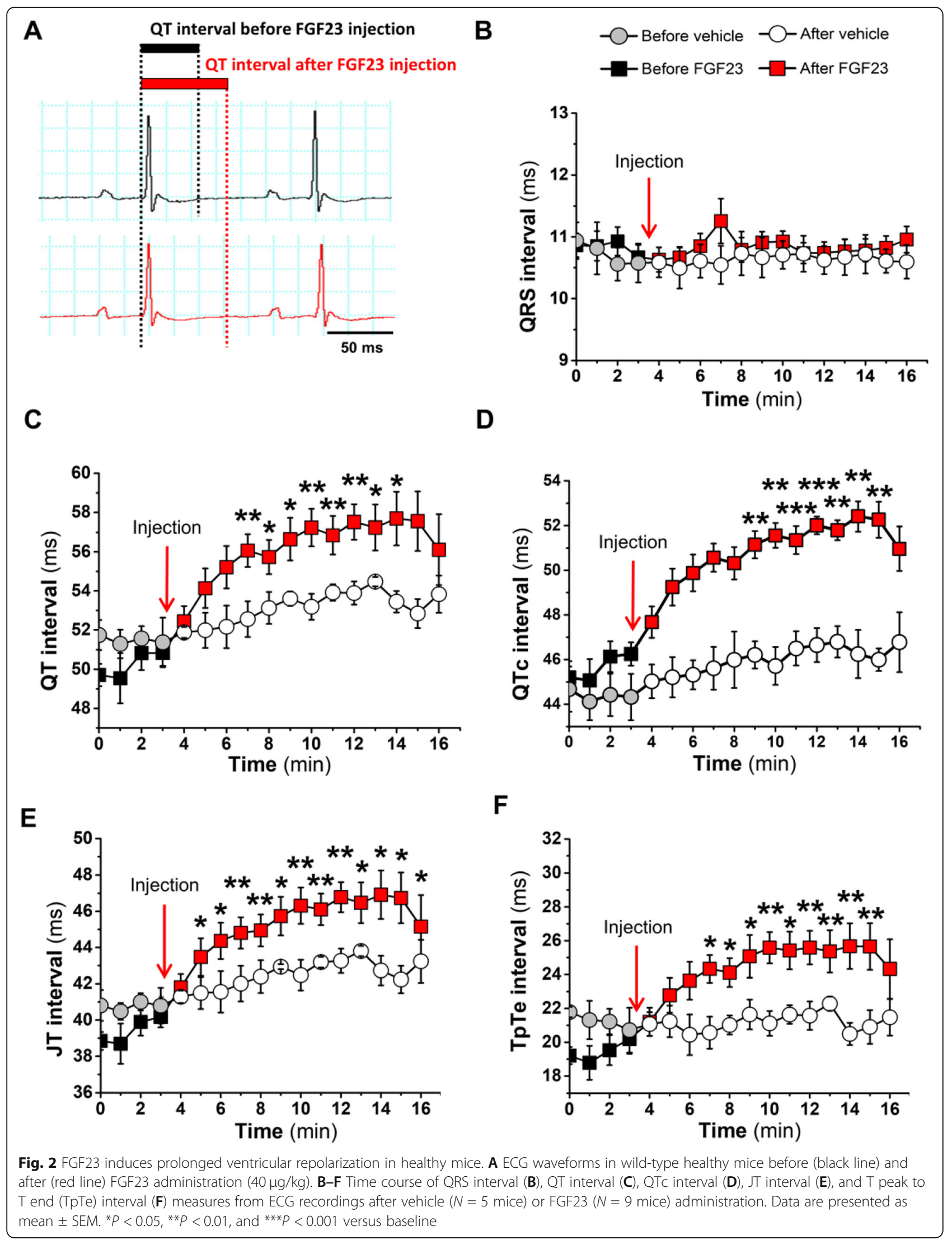


Table 2 Macroscopic and biochemical parameters in the experimental CKD model and after treatment with recombinant Klotho

\begin{tabular}{|c|c|c|c|c|}
\hline & Sham & Nfx & Sham+rKL & $\mathrm{Nfx}+\mathrm{rKL}$ \\
\hline \multicolumn{5}{|l|}{ Macroscopic parameters } \\
\hline Body weight (BW, g) & $27.7 \pm 0.6$ & $25.0 \pm 0.8$ & $26.2 \pm 0.7$ & $25.3 \pm 0.8$ \\
\hline Heart weight (HW, mg) & $206.7 \pm 10.9$ & $178.6 \pm 12.4$ & $181.0 \pm 4.2$ & $192.4 \pm 7.7$ \\
\hline $\mathrm{HW} / \mathrm{BW}$ & $7.7 \pm 0.2$ & $7.8 \pm 0.2$ & $7.2 \pm 0.2$ & $7.5 \pm 0.3$ \\
\hline Cardiomyocyte area (a.u. $\left.{ }^{2}\right)$ & $3406 \pm 123$ & $3380 \pm 146$ & $2958 \pm 141$ & $3123 \pm 128$ \\
\hline Kidney weight (mg) & $164.4 \pm 0.5$ & $142.7 \pm 0.7$ & $153.6 \pm 0.3$ & $133.1 \pm 0.9$ \\
\hline \multicolumn{5}{|l|}{ Biochemical parameters } \\
\hline Urea (mg/dL) & $51.7 \pm 3.0$ & $112.7 \pm 11.1^{* * *}$ & $42.1 \pm 3.9$ & $109.4 \pm 11.4^{\dagger+\dagger}$ \\
\hline BUN (mg/dL) & $24.2 \pm 1.4$ & $52.7 \pm 5.2^{* * *}$ & $19.7 \pm 1.8$ & $51.1 \pm 5.3^{t+t}$ \\
\hline Phosphorus (mg/dL) & $8.3 \pm 1.0$ & $7.6 \pm 0.8$ & $6.3 \pm 0.9$ & $8.2 \pm 0.9$ \\
\hline FGF23 (pg/mL) & $148.9 \pm 15.9$ & $345.4 \pm 54.2^{* *}$ & $123.0 \pm 12.0$ & $353.1 \pm 49.7^{\dagger+\dagger}$ \\
\hline
\end{tabular}

Data from 8 animals for macroscopic and biochemical parameters per experimental group are reported as mean \pm SEM. BW, body weight; HW heart weight; BUN blood urea nitrogen; FGF23, fibroblast growth factor $23 .{ }^{* *} P<0.01$, ${ }^{* * *} P<0.001 \mathrm{vs.} \mathrm{Sham;}{ }^{++\dagger} P<0.001$ vs. Sham+rKL. Sham and Nfx mice were treated with vehicle solution $(0.9 \%$ sodium chloride)

differences in phosphate levels. Analysis of ECG recordings from Sham- $T g-K l$ and $\mathrm{Nfx}-\mathrm{Tg}-\mathrm{Kl}$ mice revealed no differences in QT, QTc, JT, or TpTe intervals (Fig. 6A$\mathrm{D})$, indicating that Klotho overexpression protects against acquired prolonged ventricular repolarization in Nfx mice.

Finally, to elucidate the contribution of Klotho to the prolongation of ventricular repolarization beyond renal dysfunction, we examined ECG parameters in mice hypomorphic for Klotho $(k l / k l)$, which show very high systemic levels of FGF23, and in wild-type $(+/+)$ littermates. Macroscopic and biochemical parameters of the two groups are shown in Additional File 2. Klotho hypomorphic mice were smaller than their wild-type littermates, with lower BW and HW (both $P<0.001$, Additional File 2) but a higher $\mathrm{HW} / \mathrm{BW}$ ratio $(P<0.05$, Additional File 2). $K l / k l$ mice had impaired renal function with higher urea, BUN and FGF23 levels than $+/+$ mice $(P<0.01, P<0.01$, and $P<0.001$, respectively, Additional File 2). No changes were observed in phosphate levels between both groups, which might be due to the phosphaturic effect of the extremely high FGF23 found in $k l / k l$ mice. Analysis of ventricular repolarization in vivo revealed a significant increase in QT and QTc in $k l / k l$ mice $(P<0.001$, Fig. 6E, F). Furthermore, $k l / k l$ mice exhibited prolonged JT $(P<0.01$, Fig. $6 \mathrm{G})$ and TpTe $(P<0.001$, Fig. $6 \mathrm{H})$ intervals with respect to $+/+$ mice.

\section{Discussion}

CKD induces premature aging [47], which is frequently associated with reduced expression of the anti-aging factor Klotho [43, 48]. Aging has been shown to increase the prevalence of a wide range of pathologies including cardiovascular diseases [49], which are the main cause of death in the elderly [50], particularly in patients with
CKD [51]. In this line, fatal arrhythmias and SCD are the leading sources of mortality in patients with CKD, especially in dialysis-dependent patients [52, 53]. This latter group frequently has asymptomatic arrhythmias [54] and alterations in ventricular repolarization with significant QT interval prolongation [20]. Here, we describe for the first time a relevant association between high FGF23 levels and the presence of long QT in patients with dialysis-dependent CKD, and we show that enhancing Klotho availability protects against acquired long QT in uremic milieu a in a mouse model of CKD (Fig. 7).

Klotho-deficient mice are characterized by premature aging and reduced lifespan [11]. We found that mice with reduced Klotho expression showed prolonged QTc, $\mathrm{TpTe}$, and JT intervals. Interestingly, loss of Klotho expression in mice is linked to the development of cardiac hypertrophy [55], cardiac dysfunction [36], and a proarrhythmic phenotype [35], although Klotho is not expressed in the heart under basal conditions [11]. In the present study, we show that enhancing Klotho availability through exogenous Klotho supplementation or endogenous Klotho overexpression prevented the prolonged ventricular repolarization in an experimental CKD model, pointing to Klotho administration as a potential therapeutic strategy to preserve ventricular rhythm. In the clinical context, reduced levels of Klotho have been related to an increased risk for cardiovascular diseases [56], supporting its proposal as a predictor of all-cause mortality in the elderly [57]. Indeed, no association has been found between Klotho levels and cardiovascular mortality in the general population [58], indicating that Klotho is likely not a good biomarker of cardiovascular risk. This is in contrast to the MBD component FGF23, whose role as a cardiovascular risk biomarker is better established [59]. We found that CKD 


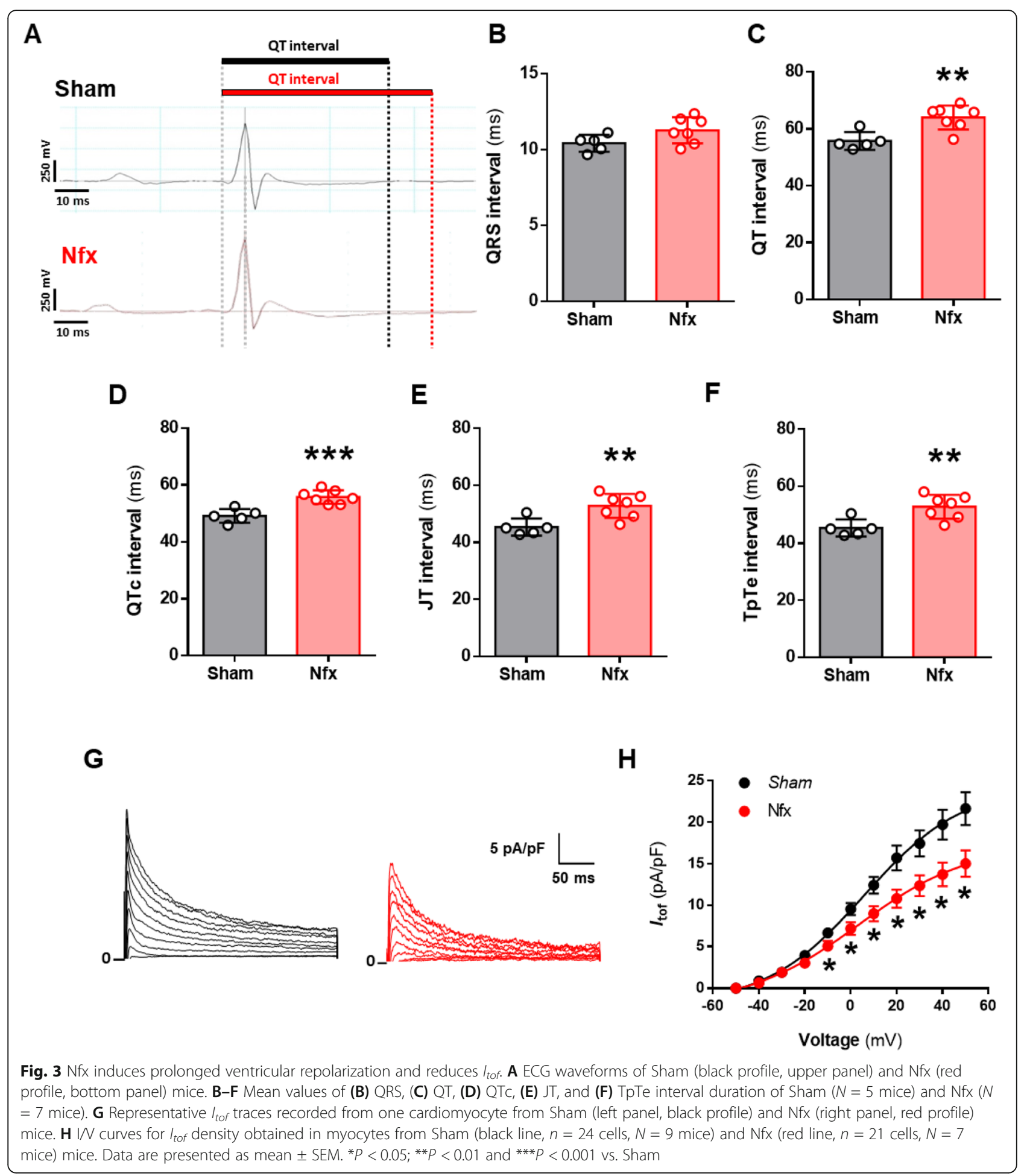

mice and Klotho hypomorphic mice in particular present high FGF23 serum levels. In the latter case, the very high systemic levels of FGF23 that accompany the defect in Klotho expression might be the primary responsible factor for the cardiac alterations related to the prolonged ventricular repolarization observed in CKD.
Most previously published reports on the cardiac effects of FGF23 have focused on its structural role based on hypertrophy development $[44,60,61]$ and on rhythm alterations almost restricted only to atrial fibrillation [62-64]. For example, treatment of the atrial cell line HL-1 with FGF23 triggers pro-arrhythmogenic events 


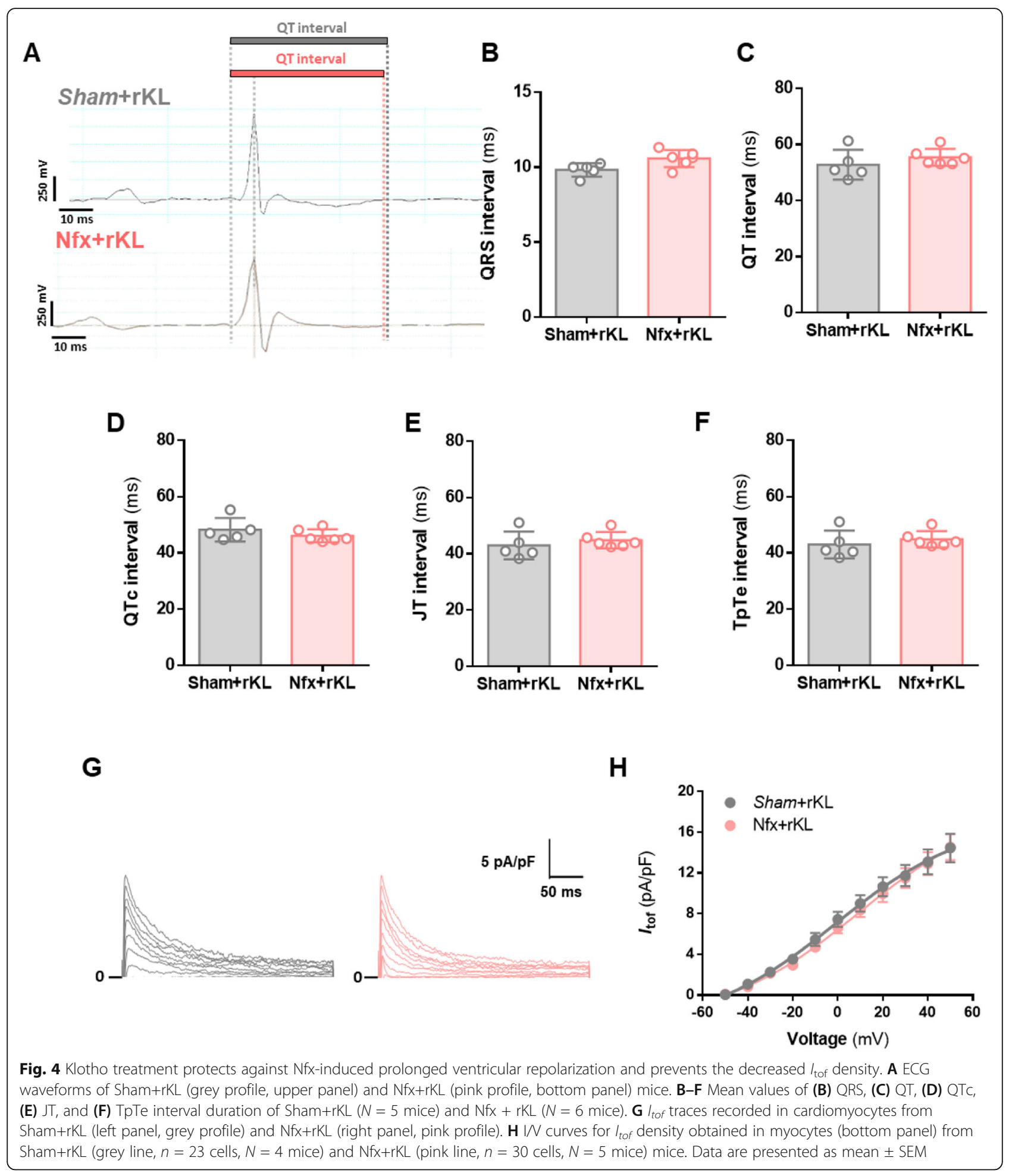

[65]. Also, it was recently demonstrated that FGF23 induces a pro-arrhythmogenic phenotype in ventricular adult cardiomyocytes by altering intracellular $\mathrm{Ca}^{2+}$ handling $[66,67]$. We establish here that FGF23 has a direct effect on ventricular repolarization in vivo. Translating these results to a clinical setting, we show for the first time to our knowledge that FGF23 levels are associated with QT interval prolongation in a cohort of patients with dialysis-dependent CKD. Prolonged QT interval appears to be common in dialysis patients $[24,68]$ and has been related to increased risk of SCD [20, 23]. Prolonged QT interval is typically a consequence of cardiac 


\section{A

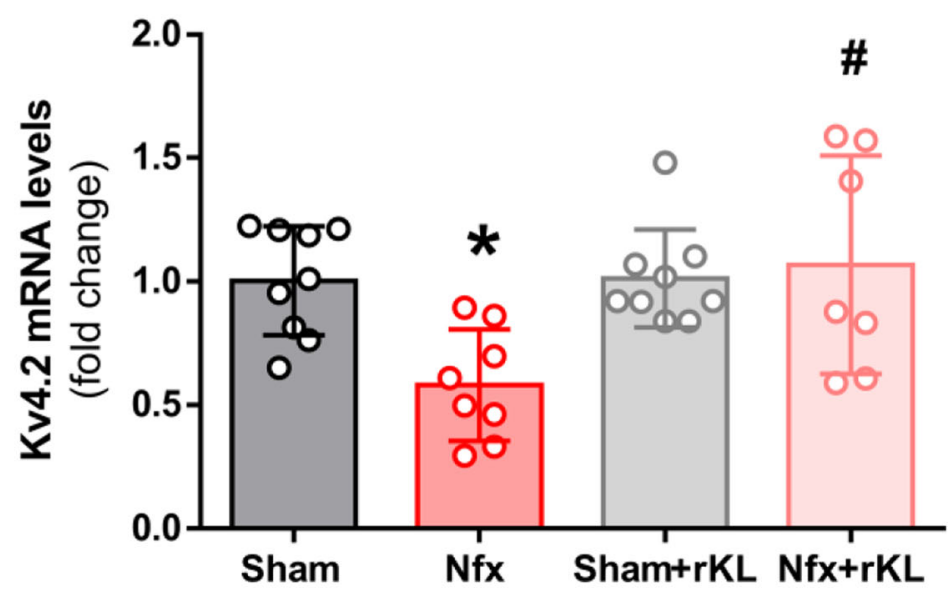

B

Neonatal mouse ventricular cardiomyocytes

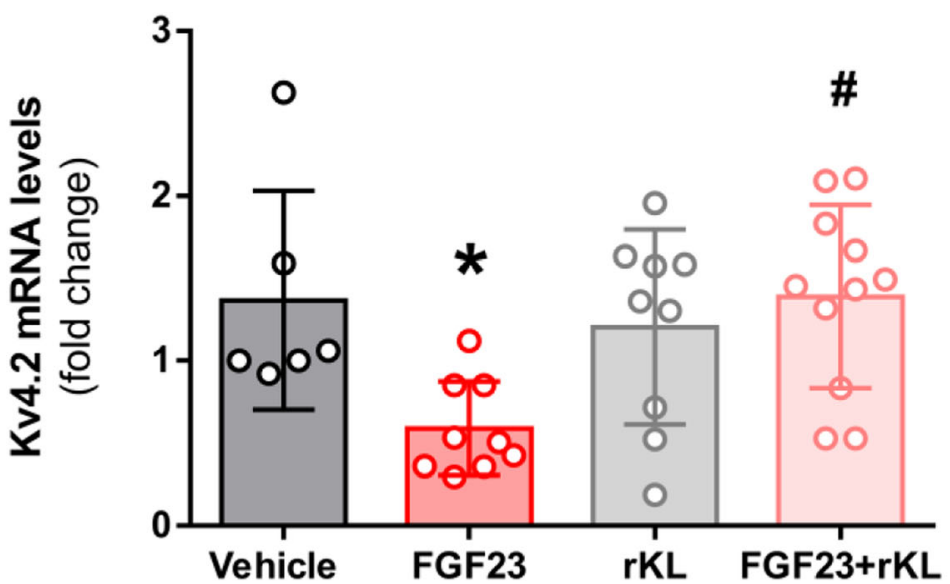

Fig. 5 Klotho prevents Kv4.2 a-subunit downregulation in ventricular myocytes from Nfx and after FGF23 incubation. A mRNA expression of Kv4.2 channel subunit in Sham ( $N=9$ mice), $N f x$ ( $N=8$ mice), Sham+rKL $(N=9$ mice), and Nfx $+r K L$ ( $N=7$ mice) mice. B mRNA expression of Kv4.2 in neonatal ventricular cardiomyocytes incubated with vehicle $(N=6$ replicate wells), FGF23 ( $N=9$ replicate wells), rKL ( $N=9$ replicate wells), and FGF23 + rKL ( $N=11$ replicate wells). Data are presented as mean \pm SEM. ${ }^{*} P<0.05$ vs. the corresponding control (Sham or vehicle-neonatal cardiomyocytes) and ${ }^{\#} P<0.05$ vs. FGF23-neonatal cardiomyocytes

structural changes [69], although some studies have described prolonged QT interval in the absence of cardiac hypertrophy [70]. Supporting this latter idea, our analysis showed no differences in the presence of left ventricular hypertrophy across FGF23 quartiles. These results together with the absence of cardiac hypertrophy in the CKD mouse model indicate that the alterations in cardiac repolarization are associated to the high FGF23 and low Klotho levels present in uremia in the absence of relevant structural cardiac remodeling, although it is important to note that our CKD model presents with other uremia-associated alterations, and, therefore, it is not possible to claim that FGF23 is the sole responsible factor for the increased QT interval in the context of CKD. That being said, intraperitoneal administration of FGF23 in healthy mice demonstrated that it can directly induce QT interval prolongation. A recent study has demonstrated that this FGF23-induced prolongation of the QT interval in healthy mice was mediated by FGFR4 [71]. However, in our experimental model of CKD, we did not find any evidence of cardiac hypertrophy development, which is usually associated to FGFR4-mediated 

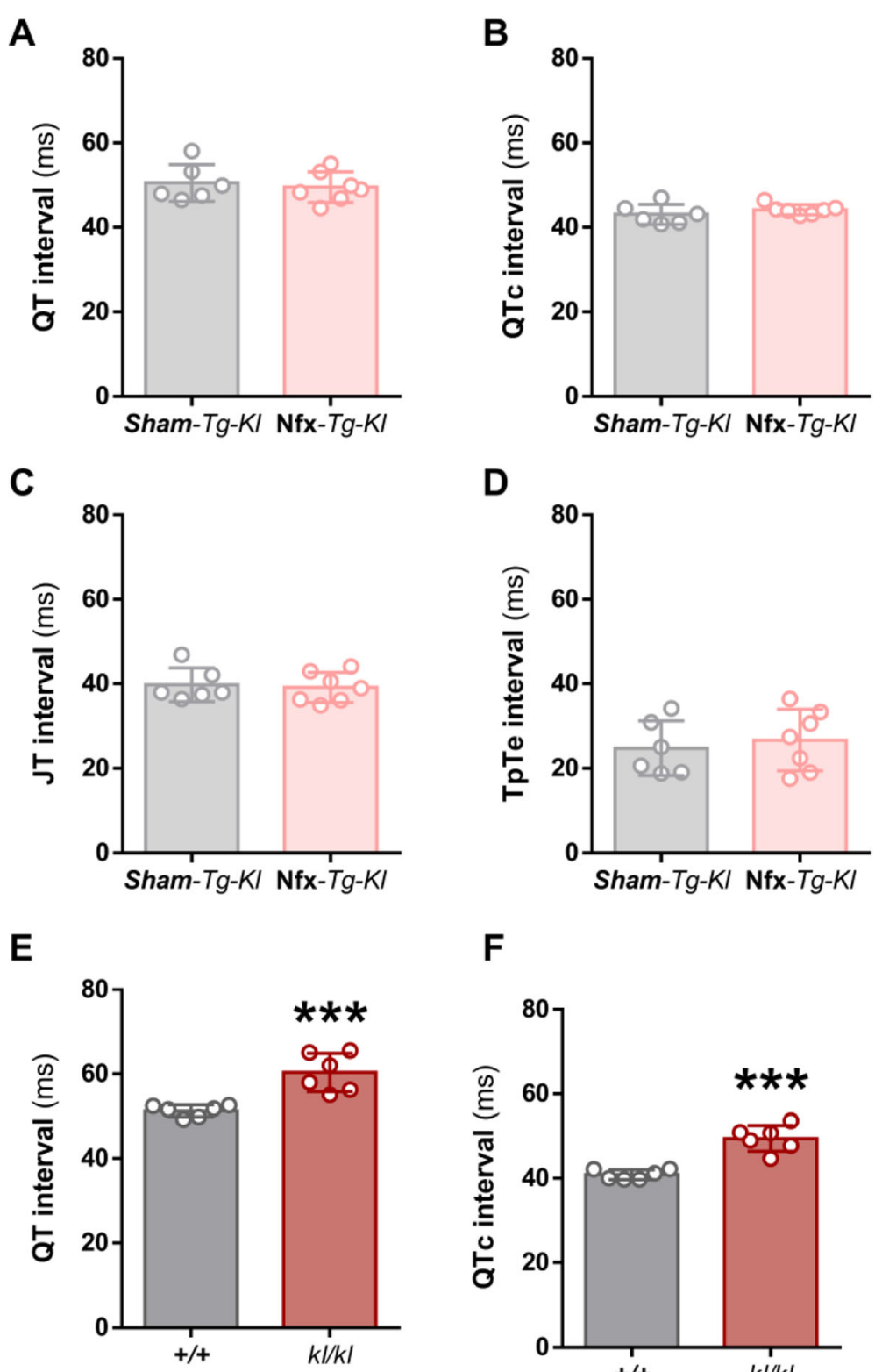

$\mathbf{F}$
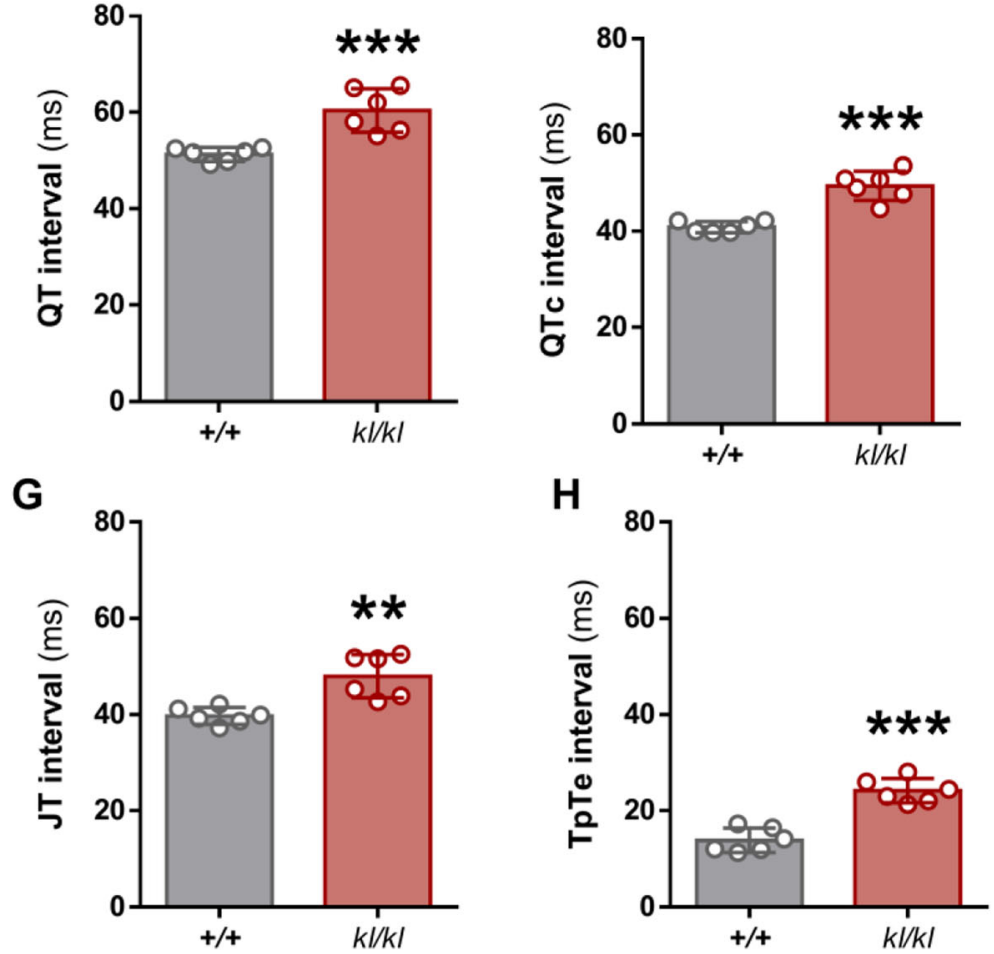

Fig. 6 Klotho overexpression prevents prolonged ventricular repolarization induced by Nfx and Klotho deficiency prolongs ventricular repolarization. A-D Mean values of A QT, B QTc, C JT, and D TpTe interval duration of Sham-Tg-kl ( $N=6$ mice), Nfx-Tg-kl ( $N=7$ mice). E-H Mean values of (E) QT, (F) QTc, (G) JT, and (H) TpTe intervals duration of $+/+\left(N=6\right.$ mice), $k / / k l$ ( $N=6$ mice). Data are presented as mean \pm SEM. ${ }^{* *} P<$ 0.01 and ${ }^{* *} P<0.001$ vs. $+/+$ 


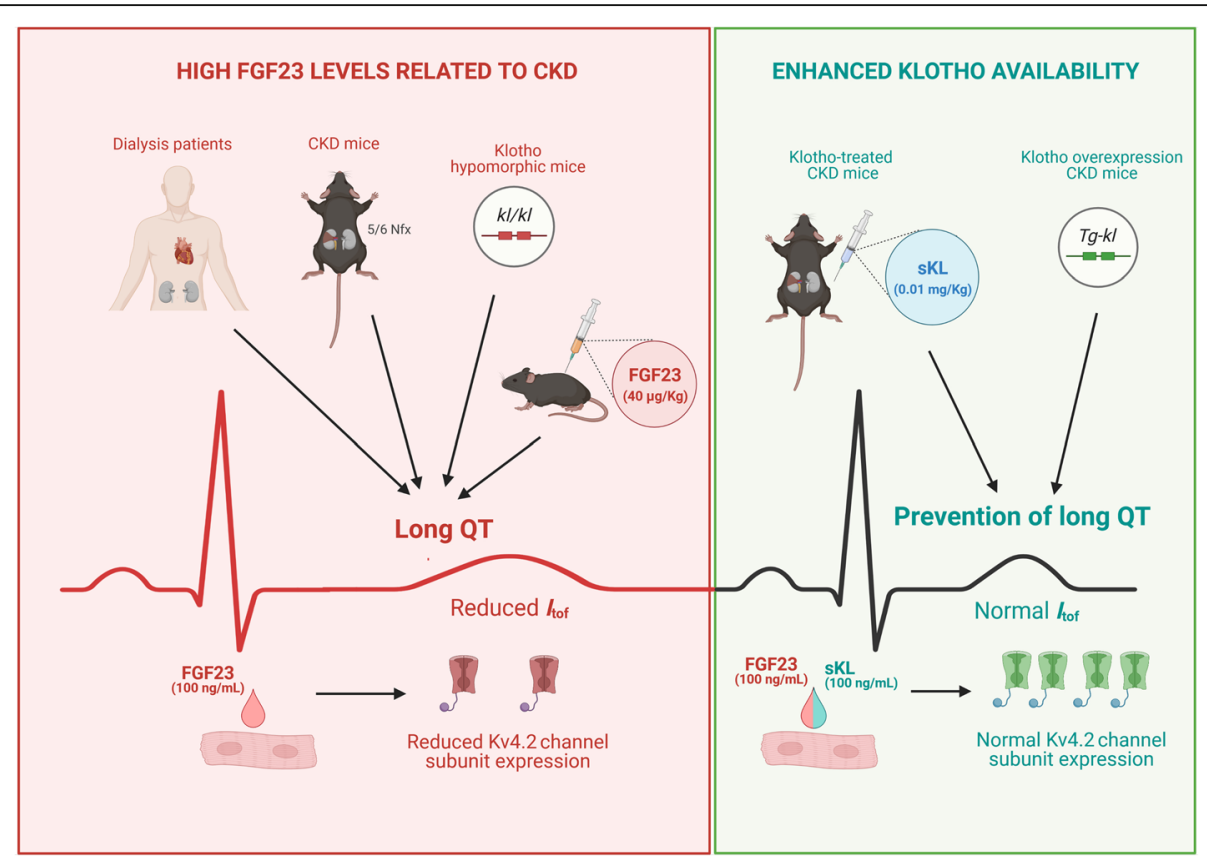

Fig. 7 Diagram representing the involvement of FGF23-Klotho axis in acquired long QT syndrome. CKD, chronic kidney disease; FGF23, fibroblast growth factor 23; Itof, fast transient outward potassium current; kl/kl, Klotho hypomorphic mice; Kv4.2, $\mathrm{K}^{+}$channel 4.2 subunit; Nfx, nephrectomy; sKL, soluble Klotho; Tg-kl, Klotho overexpression mice

FGF23 signaling. Moreover, no changes were detected in FGFR4 expression in hearts of Nfx mice (data not shown). These experimental data together with the clinical data in dialysis patients where the prevalence of LVH along FGF23 quartiles were similar support the possibility that FGF23 requires other mechanisms to induce QT prolongation. Also, no association has yet been reported between the QT interval and cardiac structure in dialysis patients [72]. The relationship between FGF23 and the development of LVH in CKD patients has been described [44], but contradictory data has been reported in dialysis patients. Some studies described an association between FGF23 and LVH in dialysis patients [73] while others authors did not find associations between serum FGF23 levels and LVH [74, 75]. Thus, the QT interval prolongation observed in our cohort might indeed be due to the increased levels of FGF23 in the dialysis patients, which is also experimentally supported by the increased QT interval duration observed in healthy mice after a single FGF23 injection.

The QT interval is not the only ECG parameter that has been associated with SCD. The TpTe interval has also been used in the measurement of the transmural dispersion of ventricular repolarization [76] and is also related to increased risk of mortality [40, 41]. We found that the TpTe interval in dialysis patients was significantly longer in Q4 FGF23 than in Q1 FGF23. A prolonged $\mathrm{TpTe}$ interval has been proposed as a predictor of ventricular arrhythmias and SCD [41, 77]. Moreover, in patients with HF, TpTe has been found to be longer in those patients with CKD [78]. Supporting these data is the finding of a significant reduction in TpTe interval after renal transplantation [79], demonstrating a reduction in the risk of developing cardiac arrhythmia after transplantation compared with those patients with endstage renal failure. Adverse electrophysiological remodeling such as abnormal $\mathrm{K}^{+}$currents is one of the mechanisms related to prolonged ventricular repolarization. Indeed, loss-of-function mutations involving the $\mathrm{K}^{+}$ current channel have been described as the cause of long QT syndrome [80, 81], and reduced $I_{\text {tof }}$ has been related to long QT syndrome in rodents $[82,83]$. In mice, $I_{t o f}$ is one of the most important current in determining ventricular repolarization duration due to the extraordinarily abbreviated action potentials [84]. Our study shows that Nfx model exhibits decreased $I_{t o f}$ density, and a significant reduction of this $\mathrm{K}^{+}$current has been found in a less aggressive CKD model in rats [85]. Moreover, similar results have been found in an established animal model of HF where a reduction in cardiomyocyte $\mathrm{K}^{+}$ current was linked to prolonged QT, TpTe, and JT intervals [39]. Downregulated $\mathrm{K}^{+}$currents might be caused by changes in $\mathrm{K}^{+}$channel expression [86] in which $\mathrm{Kv} 4.2$ is the main channel responsible for maintaining ventricular repolarization in mice [87]. Kv4.2 downregulation has been found by some authors in failing hearts [88] and has been related to the development of early arrhythmias in mice [89], including long QT phenotype 
[83]. We observed a significant reduction of Kv4.2 expression in adult cardiomyocytes from Nfx mice, and we found that treatment of neonatal ventricular cardiomyocytes with FGF23 also downregulated Kv4.2 expression. These findings mechanistically define a role for FGF23 in ventricular repolarization prolongation observed in experimental and clinical uremia.

The prolongation of QT, TpTe, and JT intervals observed in CKD mice are also present in the transgenic mice model of reduced Klotho expression that is accompanied by a marked increase in FGF23 levels. These findings point to the need for therapeutic strategies to prevent/block the effects of FGF23 on the heart in the context of uremia. Along this line, the importance of the balance between FGF23 levels and Klotho availability is gaining attraction, and several studies have demonstrated a relevant cardioprotective role of soluble Klotho in the context of cardiac hypertrophy by direct regulation of ion channels [90] or even in the context of uremic cardiomyopathy $[13,35,36]$. Moreover, it has been recently described that FGF23-induced cardiac hypertrophy in mice is attenuated by soluble Klotho administration [91]. The present work demonstrates that improving Klotho availability prevents the acquired long QT syndrome associated with CKD. Klotho-treated Nfx mice did not develop prolonged repolarization-related intervals, likely due to the prevention of reduced $I_{\text {tof. }}$ Similarly, increased endogenous Klotho availability through Klotho overexpression protected against repolarization abnormalities in $\mathrm{Nfx}$ mice. Finally, the downregulation in Kv4.2 mediated by FGF23 exposure was also blocked in cardiomyocytes pretreated with recombinant Klotho. We believe that these findings are clinically relevant as they point to Klotho not only as a mechanism linked to cardiorenal damage but also as a useful therapeutic target to prevent fatal arrhythmias triggered by FGF23 in CKD.

\section{Limitation}

A key question that remains to be solved is how the cardioprotective actions of Klotho treatment against FGF23 effect occur and whether this protection depends on the blockade of the FGF23 binding to FGFRs. In our hands, we did not observe any evidence of cardiac hypertrophy neither changes in the expression of FGFRs in the heart of CKD mice (data not shown). These results support the possibility that rKL could induce a switch in the signaling of FGF23 from FGFR4 to FGFR1 under high Klotho levels, which has been recently proposed by other authors [91, 92]. Further studies will be needed to elucidate the mechanisms underlying Klotho cardioprotection.

\section{Conclusions}

Our results support FGF23 as a promoting factor of cardiac arrhythmias related to prolonged QT interval. In this context, enhancing Klotho availability appears to be a valid therapeutic strategy to prevent acquired long QT syndrome and potentially fatal ventricular arrhythmias and SCD in CKD.

\begin{abstract}
Abbreviations
ACEi: Angiotensin-converting enzyme inhibitor; ARB: Angiotensin receptor blocker; BMI: Body mass index; BUN: Blood urea nitrogen; BW: Body weight; CaxP: Calcium-phosphorus product; CKD: Chronic kidney disease;

CQT: Corrected QT interval; DBP: Diastolic blood pressure;

ECG: Electrocardiogram; eGFR: Estimated glomerular filtration rate; FGF23: Fibroblast growth factor 23; FGFR: Fibroblast growth factor receptor; HF: Heart failure; HW: Heart weight; HR: Heart rhythm; Itof. Fast transient outward potassium current; KT: Kidney transplantation; KW: Kidney weight; LVH: Left ventricular hypertrophy; MBD: Mineral bone disorders; Nfx: Nephroctomy; rKL: Recombinant Klotho; RMSSD: Root mean square of the successive differences; SBP: Systolic blood pressure; SCD: Sudden cardiac death; SDANN: Standard Deviation of the 5 minute Average NN intervals;

SDNN: Standard deviation of the IBI of normal sinus beats; Tg-kl: Transgenic Klotho overexpressing mice; TpTe: T wave peak to T wave end
\end{abstract}

\section{Supplementary Information}

The online version contains supplementary material available at https://doi. org/10.1186/s12916-021-02209-9.

Additional file 1. Macroscopic and biochemical parameters in $\mathrm{Tg}-\mathrm{k} / \mathrm{mice}$.

Additional file 2. Macroscopic and biochemical parameters in Klotho hypomorphic mice.

\section{Acknowledgements}

We thank Dr. Monserrat Grau Sanz for her excellent assistance with experimental animal facilities, Jennifer Aceves-Ripoll, and Elisa MercadoGarcía for their technical support and Dr. Kenneth McCreath for English editing.

\section{Authors' contributions}

J.A.N-G., C.D., and G.R-H. designed and conceptualized the experiments. J.A.N-G, C.D., and G.R-H. performed the majority of the experiments. J.A.N-G., T.B-B., J.S., L.G-L., E.R-S., L.M-N., R.S-B., C.D., and G.R-H. analyzed the data. R.S-B. carried out ECGs and together with F.A. and J.A.N-G. analyzed and interpreted them. E.H., E.M-H., M.P., and J.S., studied and followed the cohort of patients. M.K-o supplied Klotho transgenic mice. M.F-V., L.M.R., H.B., C.D., and G.R-H. provided reagent and materials. J.A.N-G., C.D., and G.R-H. wrote the manuscript. All authors read and approved the manuscript.

\section{Funding}

This work was supported by projects from the Instituto de Salud Carlos III, Ministry of Economy, Industry and Competitiveness (PI17/01093, PI17/01193, PI20/00763, CP15/00129, F18/00261, CPII20/00022, SAF2017-84777-R, PID2020-113238RB-I00), from the Sociedad Española de Cardiología (SEC), and from the Fundación Renal Ínigo Alvarez de Toledo (FRIAT), co-funded by the European Regional Development Fund (Fondos FEDER).

\section{Availability of data and materials}

The datasets generating during and/or analyzed during the current study are available from the corresponding authors on reasonable request.

\section{Declarations}

Ethics approval and consent to participate

The study in patients was approved by the ethics committee of Hospital Universitario 12 de Octubre (CEl: 16/250) and was conducted in compliance with the Declaration of Helsinki. All patients signed written informed agreement before the inclusion in the study.

Experimental animal studies were performed following recommendations of the Spanish Animal Care and User Committee, according to the guidelines for ethical care and welfare (2013/175) of experimental animals of the European Union (2010/63/EU) and following the ARRIVE guidelines for 
reporting experiments involving animals [93]. Animal studies were approved by the General Direction of Agriculture and the Environment at the Environment Council of Madrid (PROEX 053/16, PROEX184/17).

\section{Consent for publication}

Not applicable

\section{Competing interests}

The authors declare that they have no competing interests.

\section{Author details}

'Cardiorenal Translational Laboratory, Institute of Research imas12, Hospital Universitario 12 de Octubre, Avenida de Córdoba s/n, 28041 Madrid, Spain. ${ }^{2}$ Cardiology Department, Hospital Universitario 12 de Octubre, Madrid, Spain. ${ }^{3}$ Facultad de Medicina, Universidad Complutense de Madrid, Madrid, Spain. ${ }^{4}$ CIBER-CV, Hospital Universitario 12 de Octubre, Madrid, Spain. ${ }^{5}$ Biomedical Research Institute Alberto Sols (CSIC-UAM)/CIBER-CV, Arturo Duperier 4, 28029 Madrid, Spain. ${ }^{6}$ Service of Nephrology, Hospital Universitario 12 de Octubre, Madrid, Spain. ${ }^{7}$ Centro Nacional de Investigaciones Cardiovasculares (CNIC), Madrid, Spain. ${ }^{8}$ Division of Anti-aging Medicine, Centre for Molecular Medicine, Jichi Medical University, Shimotsuke, Tochigi, Japan. ${ }^{9}$ IdiPAZ Institute for Health Research/Centro de Investigación Biomédica en Red de Enfermedades Cardiovasculares, CIBER-CV, Madrid, Spain. ${ }^{10}$ European University of Madrid, Madrid, Spain.

\section{Received: 20 September 2021 Accepted: 6 December 2021}

\section{Published online: 19 January 2022}

\section{References}

1. Go AS, Chertow GM, Fan D, McCulloch CE, Hsu CY. Chronic kidney disease and the risks of death, cardiovascular events, and hospitalization. N Engl J Med. 2004;351(13):1296-305. https://doi.org/10.1056/NEJMoa041031.

2. Herzog CA, Asinger RW, Berger AK, Charytan DM, Díez J, Hart RG, et al. Cardiovascular disease in chronic kidney disease. a clinical update from Kidney Disease: Improving Global Outcomes (KDIGO). Kidney Int. 2011;80(6): 572-86. https://doi.org/10.1038/ki.2011.223.

3. Wanner C, Amann K, Shoji T. The heart and vascular system in dialysis. Lancet. 2016;388(10041):276-84. https://doi.org/10.1016/S0140-6736(16)3 0508-6.

4. Block GA, Klassen PS, Lazarus JM, Ofsthun N, Lowrie EG, Chertow GM. Mineral metabolism, mortality, and morbidity in maintenance hemodialysis. J Am Soc Nephrol. 2004;15(8):2208-18. https://doi.org/10.1097/01.ASN. 0000133041.27682.A2.

5. Isakova T, Cai X, Lee J, Xie D, Wang X, Mehta R, et al. Longitudinal FGF23 trajectories and mortality in patients with CKD. J Am Soc Nephrol. 2018; 29(2):579-90. https://doi.org/10.1681/ASN.2017070772.

6. Isakova T, Xie H, Yang W, Xie D, Anderson AH, Scialla J, et al. Fibroblast growth factor 23 and risks of mortality and end-stage renal disease in patients with chronic kidney disease. JAMA. 2011;305(23):2432-9. https://doi. org/10.1001/jama.2011.826.

7. Gutiérrez OM, Mannstadt M, Isakova T, Rauh-Hain JA, Tamez H, Shah A, et al. Fibroblast growth factor 23 and mortality among patients undergoing hemodialysis. N Engl J Med. 2008;359(6):584-92. https://doi.org/10.1056/ NEJMoa0706130.

8. Wolf M. Update on fibroblast growth factor 23 in chronic kidney disease. Kidney Int. 2012;82(7):737-47. https://doi.org/10.1038/ki.2012.176.

9. Marthi A, Donovan K, Haynes R, Wheeler DC, Baigent C, Rooney CM, et al. Fibroblast growth factor-23 and risks of cardiovascular and noncardiovascular diseases: a meta-analysis. Journal of the American Society of Nephrology. 2018;29(7):2015-27. https://doi.org/10.1681/ASN.2017121334.

10. Urakawa I, Yamazaki Y, Shimada T, lijima K, Hasegawa H, Okawa K, et al. Klotho converts canonical FGF receptor into a specific receptor for FGF23. Nature. 2006:444(7120):770-4. https://doi.org/10.1038/nature05315.

11. Kuro-o M, Matsumura $Y$, Aizawa H, Kawaguchi H, Suga T, Utsugi T, et al. Mutation of the mouse klotho gene leads to a syndrome resembling ageing. Nature. 1997;390(6655):45-51. https://doi.org/10.1038/36285.

12. Chen CD, Podvin S, Gillespie E, Leeman SE, Abraham CR. Insulin stimulates the cleavage and release of the extracellular domain of Klotho by ADAM10 and ADAM17. Proc Natl Acad Sci U S A. 2007;104(50):19796-801. https://doi. org/10.1073/pnas.0709805104.
13. Xie J, Yoon J, An SW, Kuro-o M, Huang CL. Soluble Klotho protects against uremic cardiomyopathy independently of fibroblast growth factor 23 and phosphate. J Am Soc Nephrol. 2015;26(5):1150-60. https://doi.org/10.1681/A SN.2014040325.

14. Pavik I, Jaeger P, Ebner L, Wagner CA, Petzold K, Spichtig D, et al. Secreted Klotho and FGF23 in chronic kidney disease Stage 1 to 5: a sequence suggested from a cross-sectional study. Nephrol Dial Transplant. 2013;28(2): 352-9. https://doi.org/10.1093/ndt/gfs460.

15. Kooman JP, Broers NJ, Usvyat L, Thijssen S, van der Sande FM, Cornelis T, et al. Out of control: accelerated aging in uremia. Nephrol Dial Transplant. 2013;28(1):48-54. https://doi.org/10.1093/ndt/gfs451.

16. Stenvinkel $P$, Larsson TE. Chronic kidney disease: a clinical model of premature aging. Am J Kidney Dis. 2013;62(2):339-51. https://doi.org/10.1 053/j.ajkd.2012.11.051.

17. Foley RN, Parfrey PS, Sarnak MJ. Clinical epidemiology of cardiovascular disease in chronic renal disease. Am J Kidney Dis. 1998;32(5 Suppl 3):S112-9. https://doi.org/10.1053/ajkd.1998.v32.pm9820470.

18. Dhingra R, Vasan RS. Age as a risk factor. Med Clin North Am. 2012;96(1):8791. https://doi.org/10.1016/j.mcna.2011.11.003.

19. Charytan DM, Foley R, McCullough PA, Rogers JD, Zimetbaum P, Herzog CA, et al. Committees Mla: Arrhythmia and sudden death in hemodialysis patients: protocol and baseline characteristics of the monitoring in dialysis study. Clin J Am Soc Nephrol. 2016;11(4):721-34. https://doi.org/10.2215/ CJN.09350915.

20. Coll M, Ferrer-Costa C, Pich S, Allegue C, Rodrigo E, Fernández-Fresnedo G, et al. Martinez de Francisco AL, Ortega I et al: Role of genetic and electrolyte abnormalities in prolonged QTc interval and sudden cardiac death in end-stage renal disease patients. PLoS One. 2018;13(7):e0200756. https://doi.org/10.1371/journal.pone.0200756.

21. Priori SG, Aliot E, Blomstrom-Lundqvist C, Bossaert L, Breithardt G, Brugada $P$, et al. Task force on sudden cardiac death of the European Society of Cardiology. Eur Heart J. 2001;22(16):1374-450. https://doi.org/10.1053/euhj.2 001.2824.

22. Patanè S, Marte F, Di Bella G, Currò A, Coglitore S. QT interval prolongation, torsade de pointes and renal disease. Int J Cardiol. 2008;130(2):e71-3. https://doi.org/10.1016/j.ijcard.2007.11.070.

23. Kuo HL, Liu YL, Liang CC, Chang CT, Wang SM, Liu JH, et al. Prolonged QT interval is linked to all-cause and cardiac mortality in chronic peritoneal dialysis patients. Nephrology (Carlton). 2017;22(6):436-40. https://doi.org/1 $0.1111 /$ nep. 12808

24. Matsumoto Y, Mori Y, Kageyama S, Arihara K, Sato H, Nagata K, et al. Changes in QTc interval in long-term hemodialysis patients. PLoS One. 2019;14(1):e0209297. https://doi.org/10.1371/journal.pone.0209297.

25. Genovesi S, Rossi E, Nava M, Riva H, De Franceschi S, Fabbrini P, et al. A case series of chronic haemodialysis patients: mortality, sudden death, and QT interval. Europace. 2013;15(7):1025-33. https://doi.org/10.1093/europace/eus412.

26. Beaubien ER, Pylypchuk GB, Akhtar J, Biem HJ. Value of corrected QT interval dispersion in identifying patients initiating dialysis at increased risk of total and cardiovascular mortality. Am J Kidney Dis. 2002;39(4):834-42. https://doi.org/10.1053/ajkd.2002.32005.

27. Khosoosi Niaki MR, Saravi M, Oliaee F, Akbari R, Noorkhomami S, Bozorgi Rad SH, et al. Changes in QT interval before and after hemodialysis. Caspian J Intern Med. 2013;4(1):590-4.

28. Sherif KA, Abo-Salem E, Panikkath R, Nusrat M, Tuncel M. Cardiac repolarization abnormalities among patients with various stages of chronic kidney disease. Clin Cardiol. 2014;37(7):417-21. https://doi.org/10.1002/clc.22277.

29. Tisdale JE, Chung MK, Campbell KB, Hammadah M, Joglar JA, Leclerc J, et al. Nursing AHACPCotCoCCaCoCaS: Drug-induced arrhythmias: a scientific statement from the American Heart Association. Circulation. 2020;142(15): e214-33. https://doi.org/10.1161/CIR.0000000000000905.

30. Priori SG, Blomström-Lundqvist C, Mazzanti A, Blom N, Borggrefe M, Camm J, Elliott PM, Fitzsimons D, Hatala R, Hindricks G et al: 2015 ESC Guidelines for the management of patients with ventricular arrhythmias and the prevention of sudden cardiac death: the task force for the management of patients with ventricular arrhythmias and the prevention of sudden cardiac death of the European Society of Cardiology (ESC). Endorsed by: Association for European Paediatric and Congenital Cardiology (AEPC). Eur Heart J 2015, 36(41):2793-2867.

31. Vink AS, Neumann B, Lieve KW, Sinner MF, Hofman N, El Kadi S, et al. Determination and Interpretation of the QT Interval. Circulation. 2018; 138(21):2345-58. https://doi.org/10.1161/CIRCULATIONAHA.118.033943. 
32. Rautaharju PM, Surawicz B, Gettes LS, Bailey JJ, Childers R, Deal BJ, Gorgels A, Hancock EW, Josephson M, Kligfield P et al: AHA/ACCF/HRS recommendations for the standardization and interpretation of the electrocardiogram: part IV: the ST segment, T and U waves, and the QT interval: a scientific statement from the American Heart Association Electrocardiography and Arrhythmias Committee, Council on Clinical Cardiology; the American College of Cardiology Foundation; and the Heart Rhythm Society. Endorsed by the International Society for Computerized Electrocardiology. J Am Coll Cardiol 2009, 53(11):982-991.

33. Surawicz B. Will QT dispersion play a role in clinical decision-making? J Cardiovasc Electrophysiol. 1996;7(8):777-84. https://doi.org/10.1111/j.1540-81 67.1996.tb00583.x.

34. Rosenthal TM, Masvidal D, Abi Samra FM, Bernard ML, Khatib S, Polin GM, et al. Optimal method of measuring the T-peak to T-end interval for risk stratification in primary prevention. Europace. 2018;20(4):698-705. https:// doi.org/10.1093/europace/euw430.

35. Navarro-García JA, Rueda A, Romero-García T, Aceves-Ripoll J, RodríguezSánchez E, González-Lafuente L, et al. Enhanced Klotho availability protects against cardiac dysfunction induced by uraemic cardiomyopathy by regulating Ca. Br J Pharmacol. 2020;177(20):4701-19. https://doi.org/10.1111/bph.15235.

36. Hu MC, Shi M, Gillings N, Flores B, Takahashi M, Kuro-O M, et al. Recombinant a-Klotho may be prophylactic and therapeutic for acute to chronic kidney disease progression and uremic cardiomyopathy. Kidney Int. 2017;91(5):1104-14. https://doi.org/10.1016/j.kint.2016.10.034.

37. Mitchell GF, Jeron A, Koren G. Measurement of heart rate and Q-T interval in the conscious mouse. Am J Physiol. 1998;274(3):H747-51. https://doi. org/10.1152/ajpheart.1998.274.3.H747.

38. Ruiz-Hurtado G, Li L, Fernández-Velasco M, Rueda A, Lefebvre F, Wang Y, et al. Reconciling depressed Ca2+ sparks occurrence with enhanced RyR2 activity in failing mice cardiomyocytes. J Gen Physiol. 2015;146(4):295-306. https://doi.org/10.1085/jgp.201511366.

39. Tamayo M, Martín-Nunes L, Val-Blasco A. G M-Piedras MJ, Navarro-García JA Lage E, Prieto P, Ruiz-Hurtado G, Fernández-Velasco M, Delgado C: Beneficial effects of paricalcitol on cardiac dysfunction and remodelling in a model of established heart failure. Br J Pharmacol. 2020;177(14):3273-90. https://doi. org/10.1111/bph.15048.

40. Vehmeijer JT, Koyak Z, Vink AS, Budts W, Harris L, Silversides CK, et al. Prolonged $T$ peak - $T$ end interval is a risk factor for sudden cardiac death in adults with congenital heart disease. Congenit Heart Dis. 2019;14(6):952-7. https://doi.org/10.1111/chd.12847.

41. Xue C, Hua W, Cai C, Ding LG, Niu HX, Fan XH, et al. Predictive value of Tpeak-Tend interval for ventricular arrhythmia and mortality in heart failure patients with an implantable cardioverter-defibrillator: a cohort study. Medicine (Baltimore). 2019;98(49):e18080. https://doi.org/10.1097/MD. 0000000000018080.

42. Gagnon RF, Gallimore B. Characterization of a mouse model of chronic uremia. Urol Res. 1988;16(2):119-26. https://doi.org/10.1007/BF00261969.

43. Drew DA, Katz R, Kritchevsky S, Ix J, Shlipak M, Gutiérrez OM, et al. Association between soluble Klotho and change in kidney function: the health aging and body composition study. J Am Soc Nephrol. 2017;28(6): 1859-66. https://doi.org/10.1681/ASN.2016080828.

44. Faul C, Amaral AP, Oskouei B, Hu MC, Sloan A, Isakova T, et al. FGF23 induces left ventricular hypertrophy. J Clin Invest. 2011;121(11):4393-408. https://doi.org/10.1172/JCl46122.

45. Navarro-García JA, Delgado C, Fernández-Velasco M, Val-Blasco A, Rodríguez-Sánchez E, Aceves-Ripoll J, et al. Fibroblast growth factor-23 promotes rhythm alterations and contractile dysfunction in adult ventricular cardiomyocytes. Nephrol Dial Transplant. 2019;34(11):1864-75. https://doi. org/10.1093/ndt/gfy392.

46. Banyasz T, Lozinskiy I, Payne CE, Edelmann S, Norton B, Chen B, et al. Transformation of adult rat cardiac myocytes in primary culture. Exp Physiol. 2008;93(3):370-82. https://doi.org/10.1113/expphysiol.2007.040659.

47. Kooman JP, van der Sande FM, Leunissen KM: Kidney disease and aging: a reciprocal relation. Exp Gerontol 2017, 87(Pt B):156-159.

48. Zeng $Y$, Wang PH, Zhang M, Du JR. Aging-related renal injury and inflammation are associated with downregulation of Klotho and induction of RIG-I/NF-kB signaling pathway in senescence-accelerated mice. Aging Clin Exp Res. 2016;28(1):69-76. https://doi.org/10.1007/s40520-015-0371-y.

49. Sniderman AD, Furberg CD. Age as a modifiable risk factor for cardiovascular disease. Lancet. 2008;371(9623):1547-9. https://doi.org/10.101 6/S0140-6736(08)60313-X.
50. Heron M. Deaths: leading causes for 2017. Natl Vital Stat Rep. 2019;68(6):177.

51. Tonelli M, Wiebe N, Culleton B, House A, Rabbat C, Fok M, et al. Chronic kidney disease and mortality risk: a systematic review. J Am Soc Nephrol. 2006;17(7):2034-47. https://doi.org/10.1681/ASN.2005101085.

52. Banerjee D. Sudden cardiac death in haemodialysis: clinical epidemiology and mechanisms. J Electrocardiol. 2016;49(6):843-7. https://doi.org/10.1016/j. jelectrocard.2016.07.016.

53. Lai AC, Bienstock SW, Sharma R, Skorecki K, Beerkens F, Samtani R, et al. A personalized approach to chronic kidney disease and cardiovascular disease: JACC Review Topic of the Week. J Am Coll Cardiol. 2021;77(11):1470-9. https://doi.org/10.1016/j.jacc.2021.01.028.

54. Verde E. Pérez de Prado A, López-Gómez JM, Quiroga B, Goicoechea M, García-Prieto A, Torres E, Reque J, Luño J: Asymptomatic Intradialytic Supraventricular Arrhythmias and Adverse Outcomes in Patients on Hemodialysis. Clin J Am Soc Nephrol. 2016;11(12):2210-7. https://doi.org/1 $0.2215 /$ CJN.04310416

55. Leifheit-Nestler M, Richter B, Basaran M, Nespor J, Vogt I, Alesutan I, et al. Impact of altered mineral metabolism on pathological cardiac remodeling in elevated fibroblast growth factor 23. Front Endocrinol (Lausanne). 2018;9: 333. https://doi.org/10.3389/fendo.2018.00333.

56. Semba RD, Cappola AR, Sun K, Bandinelli S, Dalal M, Crasto C, et al. Plasma Klotho and cardiovascular disease in adults. J Am Geriatr Soc. 2011;59(9): 1596-601. https://doi.org/10.1111/j.1532-5415.2011.03558.x

57. Semba RD, Cappola AR, Sun K, Bandinelli S, Dalal M, Crasto C, et al. Plasma Klotho and mortality risk in older community-dwelling adults. J Gerontol A Biol Sci Med Sci. 2011;66(7):794-800. https://doi.org/10.1093/gerona/glr058.

58. Brandenburg VM, Kleber ME, Vervloet MG, Larsson TE, Tomaschitz A, Pilz S, et al. SOLUBLE Klotho and mortality: the Ludwigshafen Risk and Cardiovascular Health Study. Atherosclerosis. 2015;242(2):483-9. https://doi. org/10.1016/j.atherosclerosis.2015.08.017.

59. Vázquez-Sánchez S, Poveda J, Navarro-García JA, González-Lafuente L, Rodríguez-Sánchez E, Ruilope LM, et al. An overview of FGF-23 as a novel candidate biomarker of cardiovascular risk. Front Physiol. 2021;12:632260. https://doi.org/10.3389/fphys.2021.632260.

60. Grabner A, Amaral AP, Schramm K, Singh S, Sloan A, Yanucil C, et al. Activation of cardiac fibroblast growth factor receptor 4 causes left ventricular hypertrophy. Cell Metab. 2015;22(6):1020-32. https://doi.org/10.1 016/j.cmet.2015.09.002.

61. Leifheit-Nestler M, Große Siemer R, Flasbart K, Richter B, Kirchhoff F, Ziegler $\mathrm{WH}$, et al. Induction of cardiac FGF23/FGFR4 expression is associated with left ventricular hypertrophy in patients with chronic kidney disease. Nephrol Dial Transplant. 2016;31(7):1088-99. https://doi.org/10.1093/ndt/gfv421.

62. Mathew JS, Sachs MC, Katz R, Patton KK, Heckbert SR, Hoofnagle AN, et al. Fibroblast growth factor-23 and incident atrial fibrillation: the Multi-Ethnic Study of Atherosclerosis (MESA) and the Cardiovascular Health Study (CHS). Circulation. 2014;130(4):298-307. https://doi.org/10.1161/CIRCULATIONA HA.113.005499.

63. Alonso A, Misialek JR, Eckfeldt JH, Selvin E, Coresh J, Chen LY, et al. Circulating fibroblast growth factor-23 and the incidence of atrial fibrillation: the Atherosclerosis Risk in Communities study. J Am Heart Assoc. 2014;3(5): e001082. https://doi.org/10.1161/JAHA.114.001082.

64. Lind L, Sundström J, Stenemo M, Hagström E, Ärnlöv J. Discovery of new biomarkers for atrial fibrillation using a custom-made proteomics chip. Heart. 2017;103(5):377-82. https://doi.org/10.1136/heartjnl-2016-309764.

65. Kao YH, Chen YC, Lin YK, Shiu RJ, Chao TF, Chen SA, et al. FGF-23 dysregulates calcium homeostasis and electrophysiological properties in $\mathrm{HL}$ 1 atrial cells. Eur J Clin Invest. 2014;44(8):795-801. https://doi.org/10.1111/ eci.12296.

66. Navarro-García JA, Delgado C, Fernández-Velasco M, Val-Blasco A, Rodríguez-Sánchez E, Aceves-Ripoll J, et al. Fibroblast growth factor-23 promotes rhythm alterations and contractile dysfunction in adult ventricular cardiomyocytes. Nephrol Dial Transplant. 2019;34(11):1864-75. https://doi. org/10.1093/ndt/gfy392.

67. Lindner M, Mehel H, David A, Leroy C, Burtin M, Friedlander G, et al. Fibroblast growth factor 23 decreases PDE4 expression in heart increasing the risk of cardiac arrhythmia; Klotho opposes these effects. Basic Res Cardiol. 2020;115(5):51. https://doi.org/10.1007/s00395-020-0810-6.

68. Kim ED, Watt J, Tereshchenko LG, Jaar BG, Sozio SM, Kao WHL, et al. Associations of serum and dialysate electrolytes with QT interval and prolongation in incident hemodialysis: the Predictors of Arrhythmic and 
Cardiovascular Risk in End-Stage Renal Disease (PACE) study. BMC Nephrol 2019;20(1):133. https://doi.org/10.1186/s12882-019-1282-5.

69. Gao C, Yang D. Electrical inhomogeneity in left ventricular hypertrophy. Cell Biochem Biophys. 2014;69(3):399-404. https://doi.org/10.1007/s12013-0149850-6.

70. Yenerçağ M, Arslan U. Tp-e interval and Tp-e/QT ratio and their association with left ventricular diastolic dysfunction in Fabry disease without left ventricular hypertrophy. J Electrocardiol. 2020;59:20-4. https://doi.org/10.101 6/j.jelectrocard.2019.12.007

71. Graves JM, Vallejo JA, Hamill CS, Wang D, Ahuja R, Patel S, et al. Fibroblast growth factor 23 (FGF23) induces ventricular arrhythmias and prolongs QTC interval in mice in an FGF receptor 4-dependent manner. Am J Physiol Heart Circ Physiol. 2021;320(6):H2283-94. https://doi.org/10.1152/ajpheart. 00798.2020.

72. Khaledifar A, Momeni A, Hasanzadeh K, Amiri M, Sedehi M. Association of corrected QT and QT dispersion with echocardiographic and laboratory findings in uremic patients under chronic hemodialysis. J Cardiovasc Echogr. 2014;24(3):78-82. https://doi.org/10.4103/2211-4122.143972.

73. Seeherunvong W, Abitbol CL, Chandar J, Rusconi P, Zilleruelo GE, Freundlich M. Fibroblast growth factor 23 and left ventricular hypertrophy in children on dialysis. Pediatr Nephrol. 2012;27(11):2129-36. https://doi.org/10.1007/ s00467-012-2224-7.

74. Nassiri AA, Hakemi MS, Safar-Pour R, Ahmadi A, Tohidi M, Kashani BS, et al. Association of serum intact fibroblast growth factor 23 with left ventricular mass and different echocardiographic findings in patients on hemodialysis. J Transl Int Med. 2016;4(3):135-41. https://doi.org/10.1515/jtim-2016-0030.

75. Knap B, Večerić-Haler Ž, Benedik M, Buturović-Ponikvar J, Ponikvar R, Bren AF. Fibroblast growth factor 23 and left ventricular mass index in maintenance hemodialysis patients: standard versus long nocturnal hemodialysis. Ther Apher Dial. 2013;17(4):407-11. https://doi.org/10.1111/1 744-9987.12087.

76. Antzelevitch C, Sicouri S, Di Diego JM, Burashnikov A, Viskin S, Shimizu W, et al. Does Tpeak-Tend provide an index of transmural dispersion of repolarization? Heart Rhythm. 2007;4(8):1114-6; author reply 1116-1119. https://doi.org/10.1016/j.hrthm.2007.05.028.

77. Zumhagen S, Zeidler EM, Stallmeyer B, Ernsting M, Eckardt L, Schulze-Bahr E. Tpeak-Tend interval and Tpeak-Tend/QT ratio in patients with Brugada syndrome. Europace. 2016;18(12):1866-72. https://doi.org/10.1093/europace/ euw033.

78. Oskouie SK, Prenner SB, Shah SJ, Sauer AJ. Differences in repolarization heterogeneity among heart failure with preserved ejection fraction phenotypic subgroups. Am J Cardiol. 2017;120(4):601-6. https://doi.org/10.1 016/j.amjcard.2017.05.031.

79. Monfared A, Assadian Rad M, Feizkhah M, Kazemnezhad E, Esmaeili S, Rastjou Herfeh N, et al. Comparison of Tpe changing on ECG, in pre and post dialysis and post transplantation. Nephrourol Mon. 2016;8(3):e35864. https://doi.org/10.5812/numonthly.35864.

80. Brewer KR, Kuenze G, Vanoye CG, George AL, Meiler J, Sanders CR. Structures illuminate cardiac ion channel functions in health and in long QT syndrome. Front Pharmacol. 2020;11:550. https://doi.org/10.3389/fphar.2020. 00550.

81. Abbott GW. KCNE4 and KCNE5: K(+) channel regulation and cardiac arrhythmogenesis. Gene. 2016;593(2):249-60. https://doi.org/10.1016/j.gene.2 016.07.069.

82. Nattel S, Maguy A, Le Bouter S, Yeh YH. Arrhythmogenic ion-channel remodeling in the heart: heart failure, myocardial infarction, and atrial fibrillation. Physiol Rev. 2007;87(2):425-56. https://doi.org/10.1152/physrev. 00014.2006.

83. Barry DM, Xu H, Schuessler RB, Nerbonne JM. Functional knockout of the transient outward current, long-QT syndrome, and cardiac remodeling in mice expressing a dominant-negative Kv4 alpha subunit. Circ Res. 1998; 83(5):560-7. https://doi.org/10.1161/01.RES.83.5.560

84. Tamayo M, Martin-Nunes L, Val-Blasco A, Piedras MJ, Larriba MJ, GómezHurtado N, et al. Calcitriol, the bioactive metabolite of vitamin D, increases ventricular K. Front Physiol. 2018;9:1186. https://doi.org/10.3389/fphys.2018. 01186.

85. Lee AS, Chen WY, Chan HC, Chung CH, Peng HY, Chang CM, et al. Electronegative LDL-mediated cardiac electrical remodeling in a rat model of chronic kidney disease. Sci Rep. 2017;7(1):40676. https://doi.org/10.1038/ srep40676.
86. Wickenden AD, Kaprielian R, Kassiri Z, Tsoporis JN, Tsushima R, Fishman Gl, et al. The role of action potential prolongation and altered intracellular calcium handling in the pathogenesis of heart failure. Cardiovasc Res. 1998; 37(2):312-23. https://doi.org/10.1016/S0008-6363(97)00256-3.

87. Patel SP, Campbell DL. Transient outward potassium current, 'Ito', phenotypes in the mammalian left ventricle: underlying molecular, cellular and biophysical mechanisms. J Physiol. 2005;569(Pt 1):7-39. https://doi.org/1 0.1113/jphysiol.2005.086223.

88. Gidh-Jain M, Huang B. Jain P, el-Sherif N: Differential expression of voltagegated $\mathrm{K}+$ channel genes in left ventricular remodeled myocardium after experimental myocardial infarction. Circ Res. 1996;79(4):669-75. https://doi. org/10.1161/01.RES.79.4.669.

89. Rodgers JL. Vanthenapalli S. Electrical remodeling and cardiotoxicity precedes structural and functional remodeling of mouse hearts under hyperoxia treatment. J Cell Physiol: Panguluri SK; 2020

90. Xie J, Cha SK, An SW, Kuro-O M, Birnbaumer L, Huang CL. Cardioprotection by Klotho through downregulation of TRPC6 channels in the mouse heart. Nat Commun. 2012;3(1):1238. https://doi.org/10.1038/ncomms2240.

91. Han X, Cai C, Xiao Z, Quarles LD. FGF23 induced left ventricular hypertrophy mediated by FGFR4 signaling in the myocardium is attenuated by soluble Klotho in mice. J Mol Cell Cardiol. 2020;138:66-74. https://doi.org/10.1016/j. yjmcc.2019.11.149.

92. Suassuna PGA, Cherem PM, de Castro BB, Maquigussa E, Cenedeze MA, Lovisi JCM, et al. aKlotho attenuates cardiac hypertrophy and increases myocardial fibroblast growth factor 21 expression in uremic rats. Exp Biol Med (Maywood). 2020;245(1):66-78. https://doi.org/10.1177/153537021 9894302.

93. McGrath JC, Drummond GB, McLachlan EM, Kilkenny C, Wainwright CL. Guidelines for reporting experiments involving animals: the ARRIVE guidelines. Br J Pharmacol. 2010;160(7):1573-6. https://doi.org/10.1111/j.14 76-5381.2010.00873.x

\section{Publisher's Note}

Springer Nature remains neutral with regard to jurisdictional claims in published maps and institutional affiliations.
Ready to submit your research? Choose BMC and benefit from:
- fast, convenient online submission
- thorough peer review by experienced researchers in your field
- rapid publication on acceptance
- support for research data, including large and complex data types
- gold Open Access which fosters wider collaboration and increased citations
- maximum visibility for your research: over $100 \mathrm{M}$ website views per year
At BMC, research is always in progress.
Learn more biomedcentral.com/submissions 